\title{
Guanosine triphosphate links MYC-dependent metabolic and ribosome programs in small-cell lung cancer
}

\author{
Fang Huang, ${ }^{1,2}$ Kenneth E. Huffman, ${ }^{3}$ Zixi Wang, ${ }^{2}$ Xun Wang, ${ }^{2}$ Kailong Li, ${ }^{2}$ Feng Cai, ${ }^{2}$ Chendong Yang, ${ }^{2}$ Ling Cai, ${ }^{2,4}$ Terry S. Shih, ${ }^{2}$ \\ Lauren C. Zacharias, ${ }^{2}$ Andrew Chung, ${ }^{2}$ Qian Yang, ${ }^{5}$ Milind D. Chalishazar, ${ }^{6}$ Abbie S. Ireland, ${ }^{6}$ C. Allison Stewart, ${ }^{7}$ Kasey Cargill, ${ }^{7}$ \\ Luc Girard, ${ }^{3}$ Yi Liu, ${ }^{5}$ Min Ni, ${ }^{2}$ Jian Xu, ${ }^{2}$ Xudong Wu, ${ }^{8}$ Hao Zhu, ${ }^{2}$ Benjamin Drapkin, ${ }^{9}$ Lauren A. Byers, ${ }^{7}$ Trudy G. Oliver, ${ }^{6}$
} Adi F. Gazdar, ${ }^{3}$ John D. Minna, ${ }^{3}$ and Ralph J. DeBerardinis ${ }^{2,10}$

\begin{abstract}
'Union Hospital, Tongji Medical College, Huazhong University of Science and Technology, Wuhan, China. ${ }^{2}$ Children's Medical Center Research Institute, ${ }^{3}$ Hamon Center for Therapeutic Oncology Research, Departments of Internal Medicine and Pharmacology, and Simmons Comprehensive Cancer Center, ${ }^{4}$ Department of Population and Data Sciences, and ${ }^{5}$ Department of Physiology, University of Texas Southwestern Medical Center, Dallas, Texas, USA. ${ }^{6}$ Department of Oncological Sciences, University of Utah, Huntsman Cancer Institute, Salt Lake City, Utah, USA. D. Medical Oncology, University of Texas MD Anderson Cancer Center, Houston, Texas, USA. ${ }^{8}$ Department of Cell Biology, Tianjin Medical University, 2011 Collaborative Innovation Center of Tianjin for Medical Epigenetics, Tianjin Key Laboratory of Medical Epigenetics, Tianjin, China. ${ }^{9}$ Department of Internal Medicine, University of Texas Southwestern Medical Center, Dallas, Texas, USA. ${ }^{10} \mathrm{Howard}$ Hughes Medical Institute, University of Texas Southwestern Medical Center, Dallas, Texas, USA
\end{abstract}

\begin{abstract}
MYC stimulates both metabolism and protein synthesis, but how cells coordinate these complementary programs is unknown. Previous work reported that, in a subset of small-cell lung cancer (SCLC) cell lines, MYC activates guanosine triphosphate (CTP) synthesis and results in sensitivity to inhibitors of the CTP synthesis enzyme inosine monophosphate dehydrogenase (IMPDH). Here, we demonstrated that primary MYC ${ }^{\text {hi }}$ human SCLC tumors also contained abundant guanosine nucleotides. We also found that elevated MYC in SCLCs with acquired chemoresistance rendered these otherwise recalcitrant tumors dependent on IMPDH. Unexpectedly, our data indicated that IMPDH linked the metabolic and protein synthesis outputs of oncogenic MYC. Coexpression analysis placed IMPDH within the MYC-driven ribosome program, and GTP depletion prevented RNA polymerase I (Pol I) from localizing to ribosomal DNA. Furthermore, the GTPases GPN1 and GPN3 were upregulated by MYC and directed Pol I to ribosomal DNA. Constitutively GTP-bound GPN1/3 mutants mitigated the effect of GTP depletion on Pol I, protecting chemoresistant SCLC cells from IMPDH inhibition. GTP therefore functioned as a metabolic gate tethering MYC-dependent ribosome biogenesis to nucleotide sufficiency through GPN1 and GPN3. IMPDH dependence is a targetable vulnerability in chemoresistant MYC hi SCLC.
\end{abstract}

\section{Introduction}

MYC is a protooncogene encoding a transcription factor that governs expression of genes involved in energy metabolism, biomass assimilation, and cell proliferation (1). Genomic MYC amplification occurs in $21 \%$ of human cancers, and other tumors overexpress $M Y C$ through other mechanisms (2-4). MYC contributes to tumor initiation, maintenance, and progression $(5,6)$, but is considered undruggable because it serves essential functions in nonmalignant tissues and lacks domains amenable to small-molecule targeting (7).

MYC's metabolic effectors have been proposed as therapeutic vulnerabilities (8). MYC stimulates glycolysis, glutaminolysis, and synthesis of macromolecules, particularly nucleotides (9-11). Monoallelic deletion of glutaminase $(\mathrm{Gls})$ attenuates MYC-driven liver tumorigenesis in mice (12), and loss of hexokinase 2 (Hk2)

Authorship note: AFG is deceased

Conflict of interest: The authors have declared that no conflict of interest exists. Copyright: ( 2021, American Society for Clinical Investigation.

Submitted: May 6, 2020; Accepted: October 15, 2020; Published: January 4, 2021.

Reference information: / Clin Invest. 2021;131(1):e139929.

https://doi.org/10.1172/JCl139929. and lactate dehydrogenase-A (Ldha) also blunt tumor progression in mice overexpressing MYC (13-15).

MYC-dependent translation is a key determinant of MYC's oncogenic activity. MYC stimulates protein synthesis by promoting ribosome biogenesis, transfer RNA (tRNA) synthesis, and translation initiation (16-18). MYC activates RNA polymerase I and III (Pol I and Pol III) to generate rRNAs and tRNAs $(19,20)$ and regulates translation initiation through multiple mechanisms (21).

It is significant that MYC concurrently regulates ribosome biogenesis and metabolism because the demand of ribosome synthesis is substantial. Ribosomes account for up to $80 \%$ of cellular RNA and one-third of dry mass. It is unclear how cancer cells with MYC as an oncogenic driver ("oncogenic MYC") synchronize ribosome biogenesis with the metabolic state. Endogenous MYC is regulated by signaling pathways to adapt to nutrient status (22-24), but it is unknown whether these mechanisms exist in tumors with oncogenic MYC. In such tumors, nodes connecting metabolism and ribosome biogenesis would be attractive therapeutic targets because blocking these activities would suppress multiple MYC outputs simultaneously.

Small-cell lung cancer (SCLC) is among the most lethal forms of cancer. Although $60 \%-80 \%$ of patients initially respond to 
A

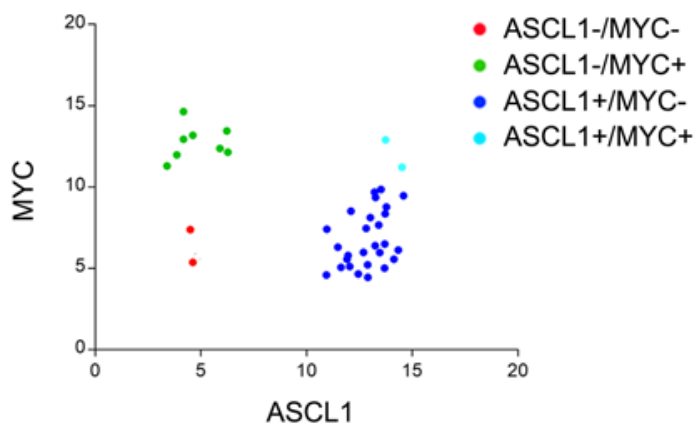

C

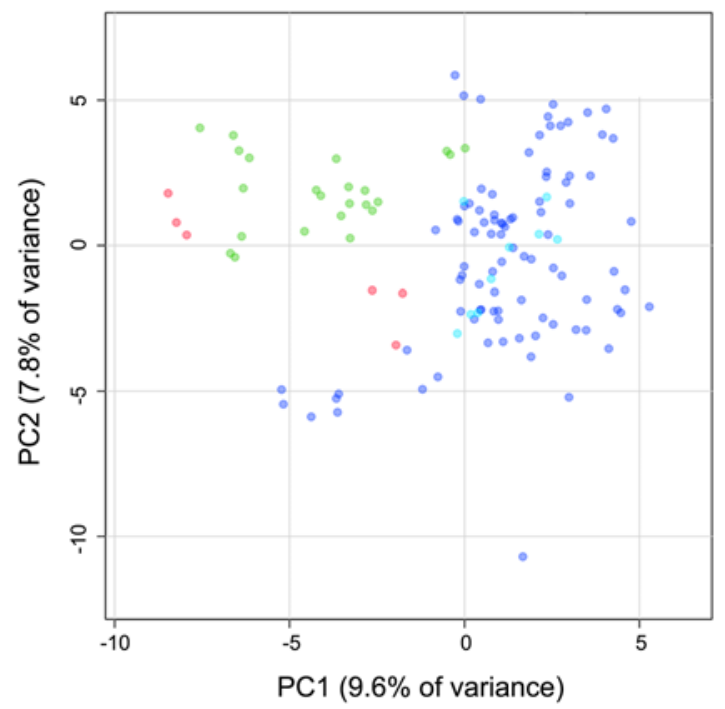

D

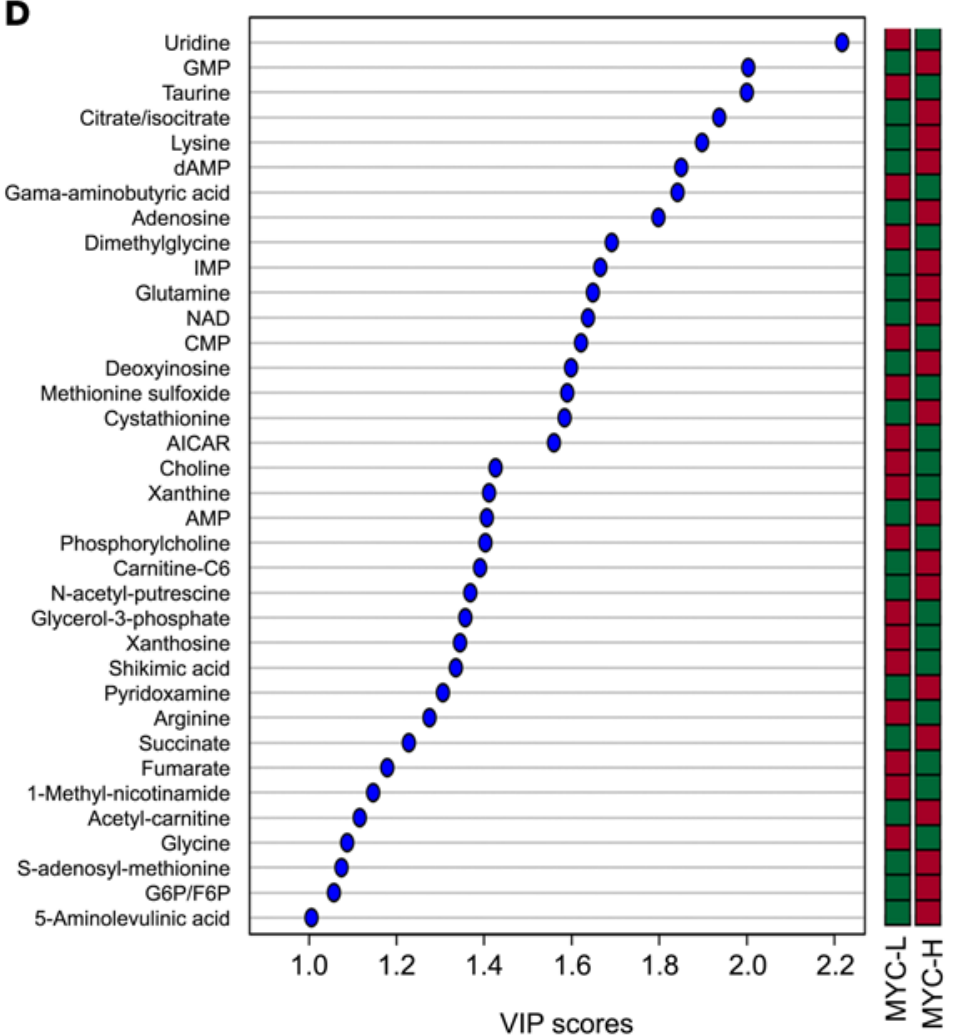

B

๘

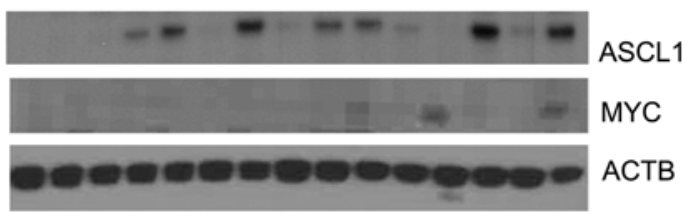

ฟ

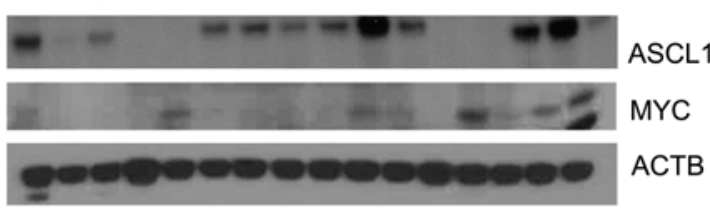

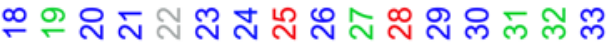

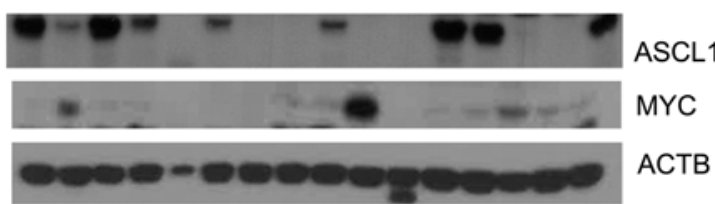

E
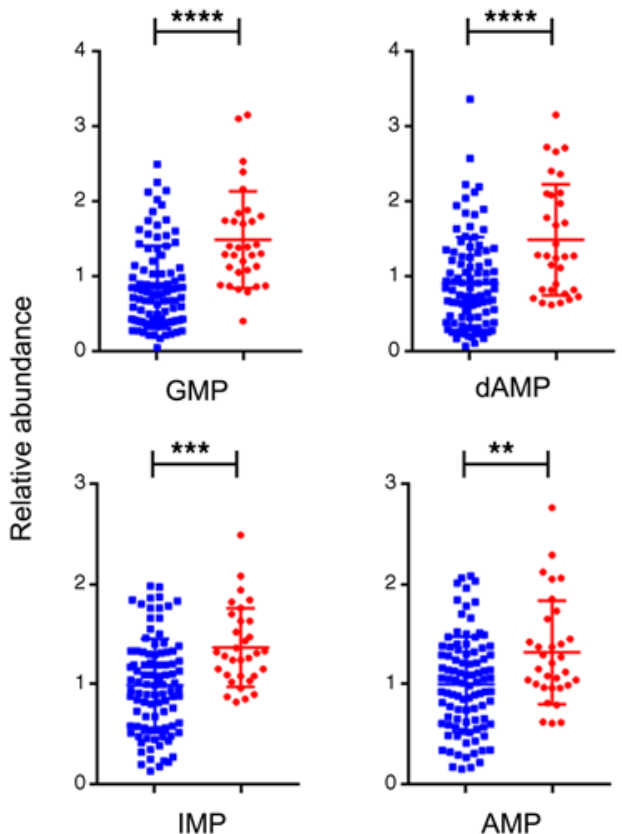

$\mathbf{F}$

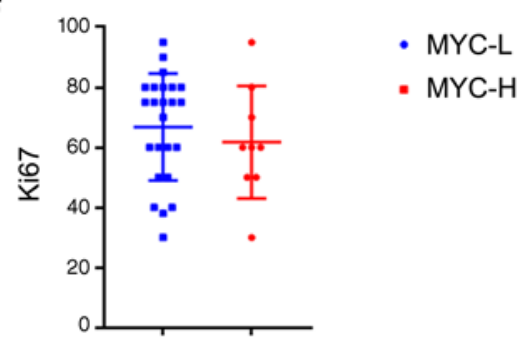


Figure 1. Distinct metabolomic subsets of primary human SCLC. (A and B) Protein abundance of ASCL1 and MYC in tumors from treatment-naive SCLC patients. Tumors labeled gray in B were excluded from further study owing to inadequate metabolite content. (C) Principal component analysis of metabolomics in tumors from $\mathbf{A}$. Individual data points are displayed for 3 fragments from each tumor. (D) Metabolites discriminating between $M Y C^{\text {hi }}$ and $M Y C^{10}$ tumors. These metabolites have variable importance in the projection (VIP) scores over 1.0, indicating statistically significant differences between the groups. The bar indicates whether each metabolite is more (red) or less abundant (green) in each group. (E) Relative abundance of purines in $\mathrm{MYC}^{\text {hi }}$ and $\mathrm{MYC}^{10}$ tumors. Individual data points are shown with mean and SD for 3 fragments from each tumor. ${ }^{* *} P<0.01$, ${ }^{* *} P<$ $0.001,{ }^{* * *} P<0.0001$. (F) Ki67 values from 33 tumors. Individual data points are shown with mean and SD. Statistical significance was assessed using a 2-tailed Student's $t$ test (E). Metabolomics was performed once. All other experiments were repeated twice or more.

platinum-etoposide chemotherapy, most relapse in less than a year with treatment-refractory SCLC. The 5-year survival rate is $6 \%$, leading the National Cancer Institute and US Congress to designate SCLC as a recalcitrant cancer $(25,26)$. Most SCLCs contain inactivation of TP53 and RB1 (27). SCLC has been classified according to expression of transcription factors related to the neuroendocrine lineage, including ASCL1, NEUROD1, YAP1, and POU2F3 (28). SCLCs frequently overexpress MYC family members, including $M Y C, M Y C N$, and $M Y C L$, and an aggressive SCLC subset is driven by oncogenic MYC, which promotes a variant histopathology with low neuroendocrine features $(25,29)$. In preclinical models, we reported that MYC-driven SCLCs are sensitive to metabolic therapies, including arginine depletion (30). We also found that SCLCs with oncogenic MYC and low ASCL1 (ASCL$\left.1^{\text {lo }} / \mathrm{MYC}^{\mathrm{hi}}\right)$ form a metabolically distinct subset with abundant purines and dependence on inosine monophosphate dehydrogenase (IMPDH), an enzyme in guanosine triphosphate (GTP) biosynthesis. In this subset, MYC is necessary and sufficient to induce IMPDH expression and dependence, and IMPDH inhibitors suppress tumor growth in xenografts and autochthonous genetically engineered mouse models (GEMMs) (31).

Here, we probed deeper into the nature of IMPDH dependence. We found that IMPDH-dependent GTP synthesis was required for Pol I to bind to rDNA and synthesize pre-rRNA, linking 2 of MYC's gene expression programs (nucleotide biosynthesis and ribosome biogenesis) and suppressing initiation of ribosome biogenesis when the nucleotide supply was inadequate. GTP acts in part through GPN1 and GPN3, 2 GTPases whose MYC-dependent expression is required for increased ribosome biogenesis. Importantly, cells derived from relapsed, chemoresistant SCLC are enriched for amplification of MYC family members, particularly $M Y C$ itself (32-34), and we found that induced chemoresistance caused SCLC cells to acquire sensitivity to IMPDH inhibition through enhanced MYC and Pol I activity. These findings suggest a therapeutic avenue for relapsed SCLC.

\section{Results}

Distinct metabolomic subsets of human primary SCLC tumors. Through a collaboration between China and the United States, we obtained clinical specimens from 47 treatment-naive SCLCs collected during lobectomy or pneumonectomy and subjected to protein and metabolite extraction. Based on an assessment of protein expression by immunoblotting, we classified 8 tumors (17\%) as $\mathrm{ASCL}_{10}^{\text {lo }} \mathrm{MYC}^{\text {hi }}$ (Figure 1, A and B). This is lower than the $40 \%$ of ASCL1 $1^{\text {lo }} / \mathrm{MYC}^{\text {hi }}$ SCLC cell lines (21 of 53 ) in the Cancer Cell Line Encyclopedia (CCLE) (31) but similar to a data set of resected primary human SCLCs (35). Four tumors were excluded from metabolomics because of inadequate metabolite content (none from the ASCL1 $1^{\text {lo }} / \mathrm{MYC}^{\text {hi }}$ group). The remaining 43 were sectioned for metabolomics. An unsupervised analysis revealed near-perfect clustering of all fragments from each tumor (Supplemental Figure 1; https://doi.org/10.1172/JCI139929DS1) and good clustering of $\mathrm{ASCL}^{1 \mathrm{lo}} / \mathrm{MYC}^{\text {hi }}$ tumors (Figure 1C). Three tumors expressing both ASCL1 and MYC were indistinguishable from ASCL1 1 hi $\mathrm{MYC}^{\text {lo }}$ tumors. The tumors aggregated into 2 metabolic families, with all but one of the ASCL1 ${ }^{10} / \mathrm{MYC}^{\text {hi }}$ tumors forming 1 group (Supplemental Figure 1), similar to metabolomic families in SCLC cell lines (31). The ASCL1 $1^{\text {lo }} / \mathrm{MYC}^{\text {hi }}$ family is characterized by abundant purines, including GMP, inosine 5'-monophosphate (IMP), and AMP (see top left of heat map in Supplemental Figure 1), all of which were also elevated in the single ASCL1 ${ }^{\text {lo }} / \mathrm{MYC}^{\text {hi }}$ tumor that did not cluster with the others. Although abundant purines were not unique to this family, every purine nucleotide monophosphate we detected (GMP, AMP, dAMP, and IMP) scored as discriminating between tumors with high and low MYC (Figure 1, D and E, and Supplemental Figure 1; supplemental material available online with this article). These tumors had similar Ki67 contents (Figure 1F), indicating that purine abundance was not simply related to enhanced proliferation. Not all metabolites accumulated in MYC $^{\text {hi }}$ tumors; the pyrimidines uridine and CMP were depleted, as were metabolites related to methylation, including choline, glycine, and dimethylglycine (Figure 1D).

As expected from the known relationship between MYC and nucleotides $(10,11)$, genes related to purine metabolism were highly correlated with MYC in pan-cancer tumor and cell line databases, and Gene Set Enrichment Analysis (GSEA) identified REACTOME_ Purine Metabolism as highly correlated with MYC (Supplemental Figure 2, A and B). The KEGG_Ribosome gene set was also correlated, as expected given MYC's role in ribosome biogenesis $(16,21)$.

Enhanced purine biosynthesis in chemoresistant SCLC. Treatment-naive MYC ${ }^{\text {hi }}$ SCLC cells and tumors are sensitive to IMPDH inhibitors (31). However, the nearly inevitable relapse after chemotherapy-induced remission in SCLC emphasizes the need for new ways to treat chemoresistant tumors. MYC activation is a common component of therapy resistance in melanoma (36), and SCLC lines derived from relapsed patients are enriched for MYC amplification (32-34). Consistent with these studies, SCLC lines derived from relapsed SCLC patients were resistant to multiple chemotherapeutics (Supplemental Figure 2C), expressed higher MYC (Supplemental Figure 2D), and more frequently had amplification of MYC family genes, especially MYC itself (Supplemental Figure 2E). Most ASCL1 ${ }^{\text {lo }} / \mathrm{MYC}^{\text {hi }}$ cell lines were derived from relapsed tumors, although some treatment-naive cell lines also belong to this group (Supplemental Figure 2F). Whole transcriptome analysis revealed enrichment of purine gene sets and specifically IMPDH1 and IMPDH2 in cells derived from relapsed versus treatment-naive SCLC (Figure 2A and Supplemental Figure 2G). Gene sets related to Pol I and protein synthesis, other processes under MYC control, were also enriched (Supplemental Figure 2G). 

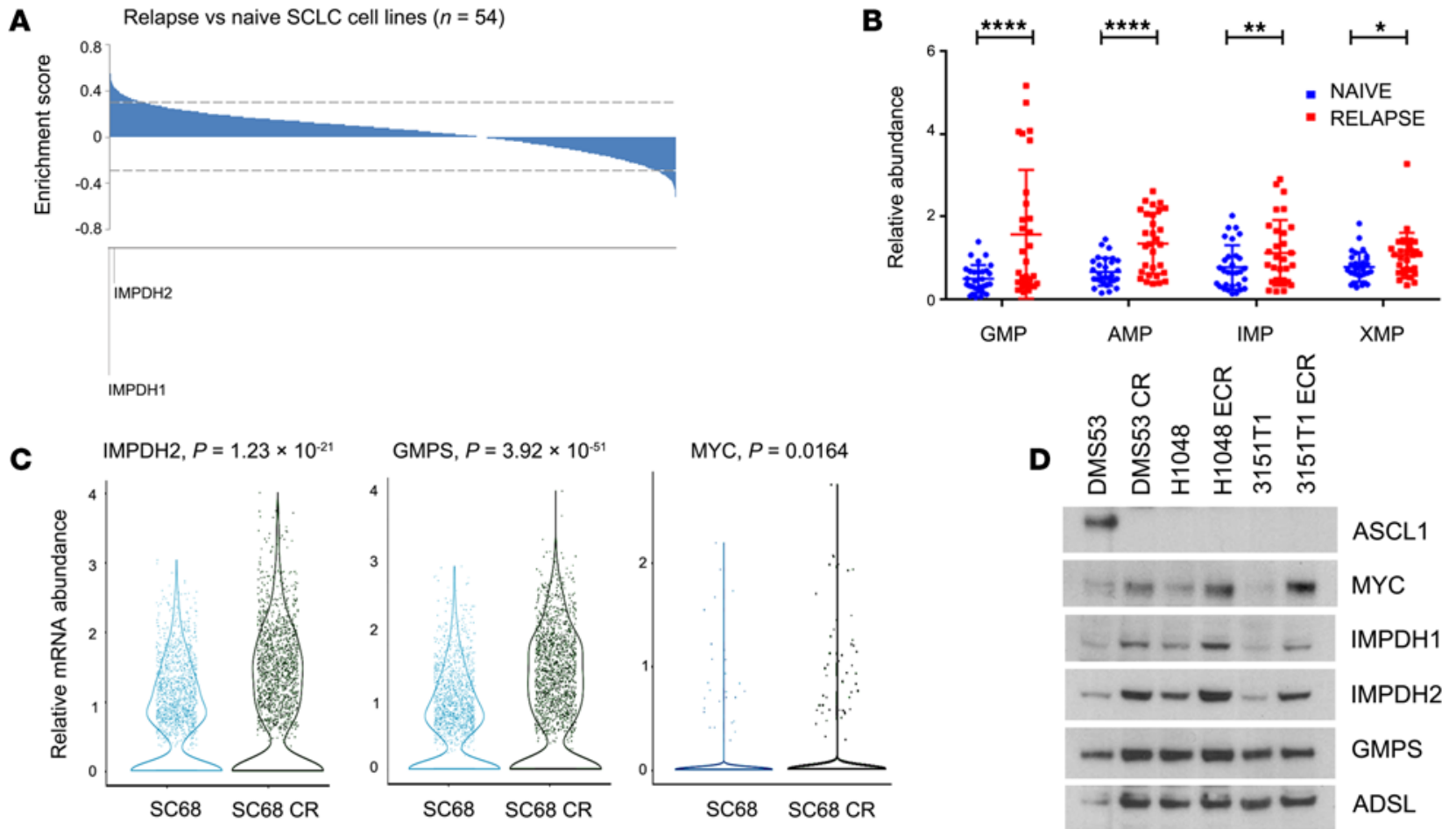

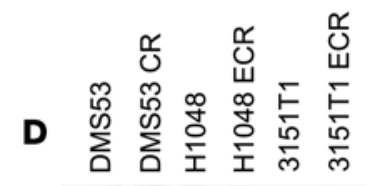
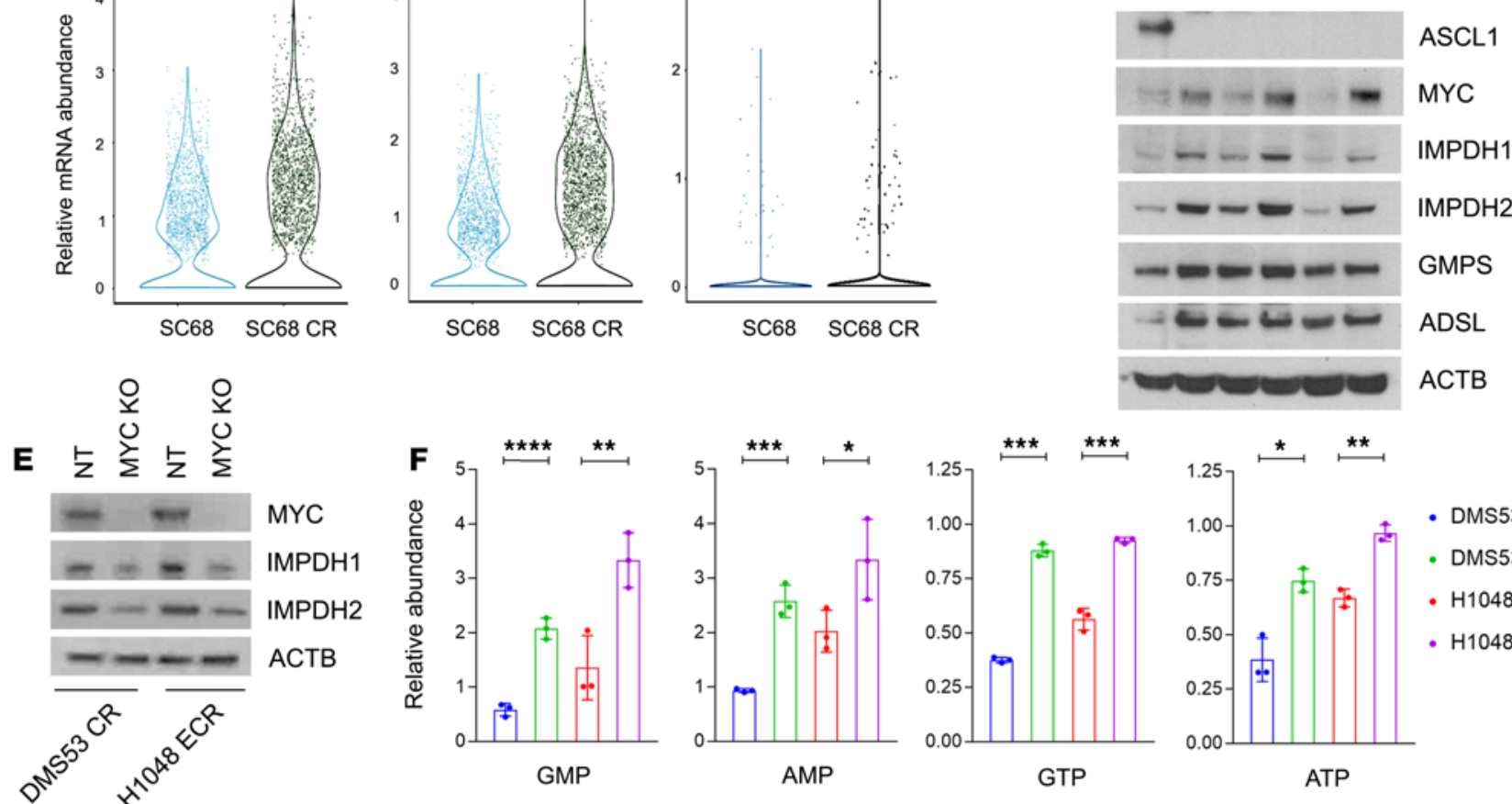

G $\quad\left[\right.$ Amide $\left.-{ }^{15} \mathrm{~N}\right]$ glutamine $->$ GMP $\mathrm{m}+3$
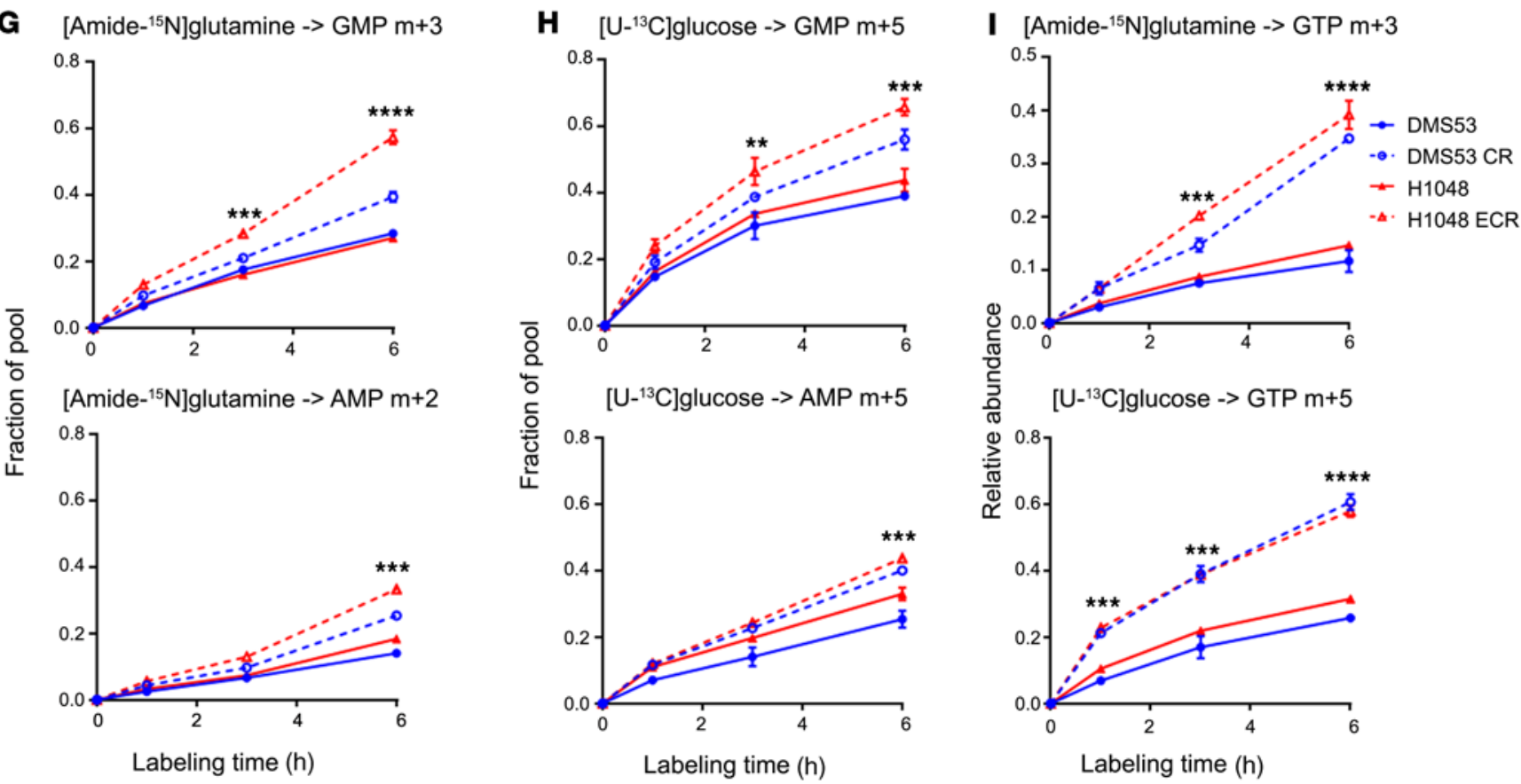
Figure 2. Enhanced purine biosynthesis in chemoresistant SCLC. (A) Enrichment scores reporting transcript abundance between 20 cell lines from relapsed patients and 34 cell lines from treatment-naive patients. Dashed lines demarcate $P=0.05$. (B) Relative abundance of GMP, AMP, IMP, and XMP in 22 of the cell lines from $\mathbf{A}$. Individual data points are shown with mean and SD for 3 cultures of each line. ${ }^{*} P<0.05,{ }^{* *} P<0.01$, ${ }^{* * * *} P<0.0001$. (C) IMPDH2, CMPS, and MYC abundance from single- cell RNA sequencing of SC68 PDX tumors and their chemoresistant counterpart SC68-CR. (D) Immunoblot analysis of ASCL1, MYC, IMPDH1, IMPDH2, GMPS, and ADSL in 3 pairs of treatment-naive and chemoresistant SCLC cell lines. CR, cisplatin resistant; ECR, etoposide and cisplatin resistant. (E) MYC, IMPDH1, and IMPDH2 expression in DMS53-CR and H1048-ECR cells with CRISPR/Cas9-mediated MYC KO or transfected with nontargeting (NT) guide RNA. (F) Relative GMP, AMP, GTP, and ATP abundance in 2 cell line pairs. ${ }^{*} P<0.05,{ }^{* *} P<0.01,{ }^{* *} P<0.001,{ }^{* * *} P<0.0001$. (G and H) Fractional labeling of GMP and AMP in pairs of treatment-naive and chemoresistant cells cultured in medium containing [amide- ${ }^{15} \mathrm{~N}$ ] glutamine (C) or [U- $\left.{ }^{13} \mathrm{C}\right]$ glucose $(\mathbf{H})$ for 1,3 , and 6 hours. ${ }^{* *} P<0.01,{ }^{* *} P<0.001,{ }^{* * *} P$ $<0.0001$. (I) Relative abundance of GTP $m+3$ and GTP $m+5$ isotopologues in pairs of treatment-naive and chemoresistant cells cultured in medium containing [amide- ${ }^{15} \mathrm{~N}$ ]glutamine or $\left[\mathrm{U}-{ }^{13} \mathrm{C}\right.$ ]glucose for 1,3 , and 6 hours. ${ }^{* * *} P$ $<0.001,{ }^{* * *} P<0.0001$. Data are shown as mean and SD (F-I). Statistical significance was assessed using a 2-tailed Student's $t$ test (B and $\mathbf{C}$ ), 1-way ANOVA with Tukey's multiple-comparison test (F-I). Metabolomics in $\mathbf{B}$ was performed once. All other experiments were repeated twice or more.

Consistent with the gene expression data, purine abundance was elevated in cells from relapsed SCLC (Figure 2B).

We next examined single-cell RNA-Seq data from SC68, a circulating tumor cell-derived xenograft (CDX) from a patient with treatment-naive SCLC. Cisplatin treatment led to regression followed by regrowth of chemoresistant tumors (SC68-CR) in mice after 6 weeks (37). Single-cell sequencing revealed elevated expression of MYC, IMPDH2, and the GTP synthesis gene GMPS in SC68-CR (Figure 2C). We also assessed treatment-naive and relapsed xenografts (MGH1514 and MGH1518) generated from the same patients before treatment and after relapse from etoposide and platinum chemotherapy (38). Expression of IMPDH1, $I M P D H 2$, and MYC family members and purine and ribosome gene sets were enhanced in xenografts generated from relapsed tumors (Supplemental Figure 2H).

To test whether acquired chemoresistance is sufficient to alter nucleotide metabolism, we cultured 3 treatment-naive SCLC cell lines at the $\mathrm{IC}_{20}$ for cisplatin alone or cisplatin and etoposide for 6 months. We used 2 human cell lines (DMS53 and H1048) and 1 cell line (3151T1) derived from $R b 1^{f / f l} p 53^{f / f l}$ SCLCs in genetically engineered mice (39). Compared to parental, treatment-naive cells, chemoresistant cells expressed increased MYC, IMPDH1, and IMPDH2, with other purine biosynthetic enzymes variably expressed (Figure 2D). Short-term cisplatin treatment in naive cells did not induce these changes (Supplemental Figure 2I). DMS53, an $\mathrm{ASCL1}^{\mathrm{hi}} / \mathrm{MYC}^{\mathrm{lo}}$ cell line, lost expression of ASCL1 upon acquiring chemotherapy resistance (Figure 2D). In DMS53-CR cells (cisplatin-resistant cells) and H1048-ECR cells (etoposide- and cisplatin-resistant cells), MYC depletion reduced IMPDH1 and IMPDH2 expression (Figure 2E). We note that DMS53 and H1048 did not require high MYC for tumorigenesis in the patient, but that MYC expression increased with chemoresistance in the cell lines. This may have allowed us to generate cells that maintained viability despite MYC depletion. Several purines, including GMP, GTP, AMP, and ATP were elevated in chemoresistant cells (Figure 2F and Supplemental Figure 3, A-C).

To compare de novo purine synthesis between chemoresistant and treatment-naive SCLC cells, we cultured DMS53 and H1048 cell line pairs with $\left[\right.$ amide $\left.-{ }^{15} \mathrm{~N}\right]$ glutamine or $\left[\mathrm{U}-{ }^{13} \mathrm{C}\right]$ glucose and followed time-dependent purine labeling (pathways in Supplemental Figure 3, D and F). GMP $\mathrm{m}+3$ and AMP $\mathrm{m}+2$ were the dominant labeled forms after incubation with [amide- $-{ }^{15} \mathrm{~N}$ ]glutamine (Supplemental Figure 3E), and GMP $\mathrm{m}+5$ and AMP $\mathrm{m}+5$ were the dominant labeled forms after incubation with $\left[\mathrm{U}-{ }^{13} \mathrm{C}\right]$ glucose (Supplemental Figure 3G). Chemoresistant cells displayed enhanced labeling, particularly in GTP (Figure 2, G-I).

$I M P D H$ dependence is a generalizable metabolic liability in $M Y C$-driven tumors. We next compared $\mathrm{IC}_{50}$ values for the IMPDH inhibitor mycophenolic acid (MPA) between treatment-naive and chemoresistant cells. Cells cultured chronically in low-dose cisplatin acquired resistance to this drug, but developed enhanced sensitivity to MPA compared with treatment-naive parental cells and with a panel of genetically diverse ASCL1 ${ }^{\text {hi }}$ cell lines (Figure 3A). Other drugs broadly affecting nucleotide synthesis, including methotrexate and 6-mercaptopurine, were also more effective in chemoresistant than treatment-naive cells, but the pyrimidine synthesis inhibitor vidofludimus was not selectively toxic (Supplemental Figure 4A). To examine sensitivities in vivo, parental and chemoresistant cell lines were injected into NSG mice, then treated with vehicle, cisplatin, or the IMPDH inhibitor mizoribine when tumors were palpable. Tumors from parental DMS53 cells were sensitive to cisplatin and resistant to mizoribine (Figure 3B), but the cisplatin-resistant line DMS53-CR displayed the opposite pattern, acquiring sensitivity to mizoribine (Figure 3B). Similar mizoribine-sensitizing effects were observed in H1048 and H69 cells, although H1048 parental tumors, which expressed MYC, were also modestly sensitive in the treatment-naive state (Supplemental Figure 4, B and C).

To assess the emergence of IMPDH dependence during chemoresistance acquired in vivo, we generated xenografts from ASCL1 ${ }^{\text {hi }}$ / MYC $^{\text {lo }} \mathrm{H} 1436$ cells derived from a treatment-naive SCLC patient. Treating these xenografts with cisplatin and etoposide resulted in an initial period of growth suppression followed by accelerated growth during the fourth cycle of therapy (Figure 3C). Implanting these posttherapy xenografts into new mice verified that they had acquired cisplatin resistance (Figure 3D). Treatment-naive H1436 xenografts were mizoribine resistant (Figure $3 C$ ), but $4 / 5$ of tumors reimplanted after chemotherapy were mizoribine sensitive (Figure $3 \mathrm{E})$. The cisplatin-resistant tumors also expressed higher levels of $M Y C, I M P D H 2$, and GMPS (Figure 3F).

To assess IMPDH dependence in MYC-driven tumors beyond SCLC, we used the inducible $L A P-M Y C$ transgenic hepatoblastoma model (40). Hepatic MYC expression was induced after birth, resulting in about $5 \%$ of the liver being occupied by malignant tissue at day 26, when i.p. mizoribine treatment was initiated at 100 $\mathrm{mg} / \mathrm{kg}$ every other day. Mizoribine nearly tripled survival in this model, mitigating abdominal distension and tumor burden (Figure 3, G-I, and Supplemental Figure 4D).

Upregulated de novo GTP biosynthesis by IMPDH promotes Pol I activity in chemoresistant SCLC cells. In addition to its roles in signaling and nucleic acid synthesis, GTP participates in unexpected 

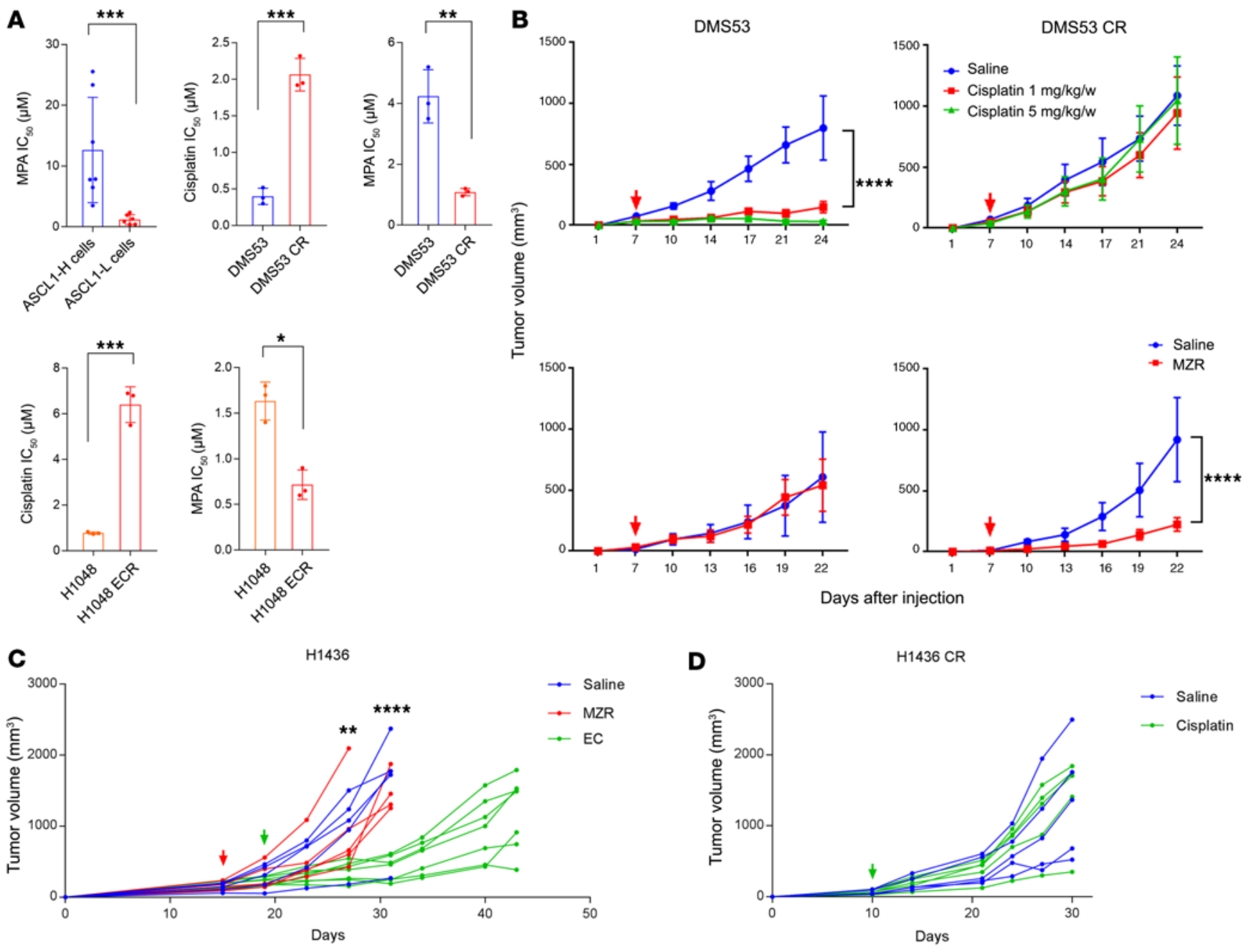

D
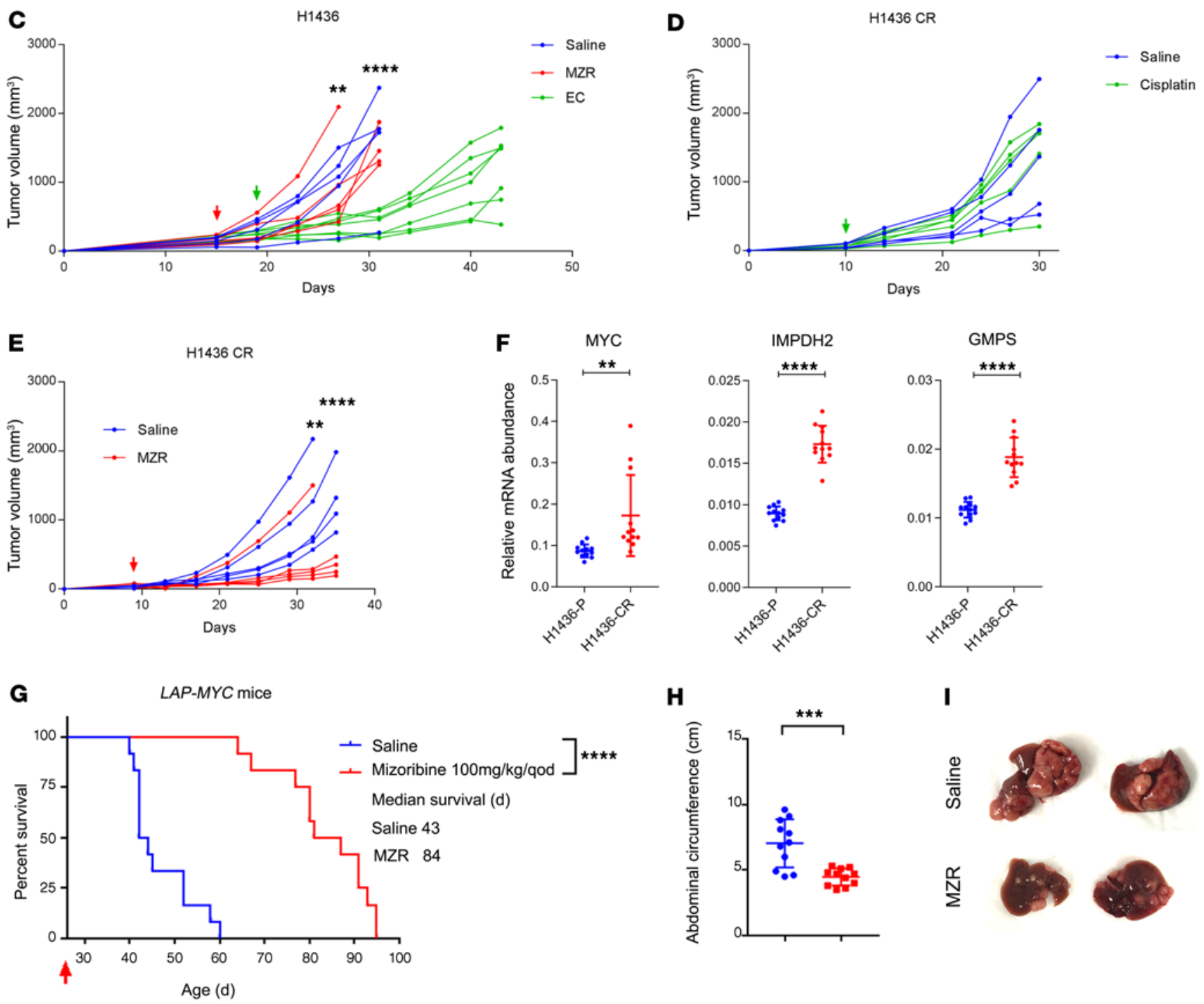
Figure 3. IMPDH dependence is a generalizable metabolic liability in MYC-driven tumors. (A) Upper left, MPA IC $C_{50}$ in $8 \mathrm{ASCL}^{\mathrm{hi}}$ and $6 \mathrm{ASCL} 1^{10}$ cell lines. Others, $\mathrm{IC}_{50}$ of MPA and cisplatin in treatment-naive and chemoresistant pairs. ${ }^{*} P<0.05$, ${ }^{* *} P<0.01,{ }^{* *} P<0.001$. (B) Xenograft growth, displaying mean and SD for tumor volume ( $n=5$ mice per group). Arrows indicate start of treatment. ${ }^{* * *} \mathrm{P}<0.0001$. (c) Treatment-naive H1436 xenograft growth. Four cycles of cisplatin $(5 \mathrm{mg} / \mathrm{kg} / \mathrm{w})$ and etoposide (10 $\mathrm{mg} / \mathrm{kg} / \mathrm{w}, \mathrm{EC})$, or mizoribine ( $100 \mathrm{mg} / \mathrm{kg} / \mathrm{d}$ ) were administered, starting at the arrow. Individual volumes are displayed. ${ }^{* *} P<0.01,{ }^{* * *} P<0.0001$. ( $\boldsymbol{D}$ and E) $\mathrm{H} 1436$ tumors pretreated with cisplatin and etoposide in C, then implanted into new mice. The arrow indicates start of treatment. Individual volumes are displayed. ${ }^{* *} P<0.01,{ }^{* * *} P<0.0001$. (F) mRNA abundance in parental $(P)$ and chemoresistant (CR) H1436 tumors. Individual data points are shown with mean and SD for 3 replicates of 4 tumors from each group. ${ }^{* *} P<0.01$, ${ }^{* * *} P<0.0001$. (C) Survival analysis of $L A P-M Y C$ mice treated with saline or mizoribine ( $n=12$ per group). Dosing began on day 26 after birth (arrow). ${ }^{* * *} P<0.0001$. (H) Abdominal circumference of $L A P$ $M Y C$ mice treated with saline or mizoribine. Measurements were taken on day 42 . ${ }^{* * *} P<0.001$. (I) Livers of $L A P-M Y C$ mice treated with saline or mizoribine. Dissections were performed on day 42 . Statistical significance was assessed using a 2-tailed Student's $t$ test (A, F, and $\mathbf{H}), 2$-way ANOVA with Tukey's multiple comparisons (B-E), log-rank (Mantel-Cox) test (G). In panels $\mathbf{C}-\mathbf{E}$, individual tumors are displayed to demonstrate variability, but statistical comparisons were made with the average and standard error among the groups. Mizoribine treatment of LAP-MYC mice was performed once. All other experiments were repeated twice or more.

processes, including nucleolar hypertrophy (41). To broadly assess GTP's roles in cancer, we used the TCGA pan-cancer gene expression data set (42) to identify gene sets whose expression correlates with GTP biosynthetic genes. Surprisingly, IMPDH2 was most highly correlated with the ribosome gene set, not the purine metabolism gene set, and this relationship was apparent in nearly every type of cancer (Figure 4A). As expected, MYC also correlated with the ribosome gene set, but this gene set correlated even more strongly with IMPDH2 than with MYC (Supplemental Figure 5A). The DepMap genetic dependency RNAi databases also identified $R R N 3$, which encodes TIF-IA, a component of the Pol I complex required for initiation of rRNA synthesis, as one of the top-scoring codependencies with IMPDH2 (Supplemental Figure 5B). These associations indicate a functional tethering of GTP synthesis to Pol I and ribosome biogenesis.

To examine this relationship in the context of chemoresistance, we used O-propargyl-puromycin (OP-Puro) to quantify protein synthesis (43). Mean OP-Puro signal was doubled in chemoresistant DMS53-CR cells relative to the treatment-naive parental DMS53 cells (Figure 4B and Supplemental Figure 5C). MPA reduced the OP-Puro signal to a level equivalent to parental cells, and the signal was restored by supplementing the cells with guanosine, which was converted to GTP via IMPDH-independent nucleotide salvage (Figure 4B). In contrast, MPA had no effect on OP-Puro signal in DMS53 cells (Supplemental Figure 5D). In both DMS53 and DMS53-CR cells, MPA depleted GTP without reducing other nucleotide triphosphates (Figure 4C and Supplemental Figure 5, E and F). MPA also depleted $80 S$ ribosome monomers and polysomes in DMS53CR cells, and guanosine reversed this depletion (Figure 4D). MPA had little effect on DMS53 cells, which had a low ribosome content (Supplemental Figure 5G). We observed similar effects in H82 cells, an $\mathrm{ASCL} 1^{\mathrm{lo}} / \mathrm{MYC}^{\text {hi }}$ cell line derived from a relapsed SCLC patient, with ribosome depletion becoming apparent after 24 hours of MPA treatment (Supplemental Figure 5, H and I).

Transcription of rDNA into pre-rRNA by Pol I is the rate-limiting step of ribosome biogenesis (44). MPA acutely suppresses the abundance of pre-rRNA, but not Pol II or Pol III transcripts, in ASCL1 ${ }^{10} /$ MYC $^{\text {hi }}$ SCLC cells (31). This also occurred in DMS53-CR cells with acquired chemoresistance, and the defect was reversed by guanosine (Figure 4E). Suppression of pre-rRNA abundance was evident within 6 hours of MPA treatment, well in advance of any effect on OP-Puro (Figure 4F), as expected if GTP depletion exerted effects on Pol I distinct from and preceding its effects on translation. To test whether loss of pre-rRNA was specific to GTP or a general response to nucleotide depletion, we treated DMS53CR cells with the GART inhibitor lometrexol (LMT), which depletes both ATP and GTP. LMT suppressed pre-rRNA abundance as expected, and supplying LMT-treated cells with guanosine rescued pre-rRNA levels despite persistent ATP depletion; adding adenosine rescued both GTP and ATP through salvage, and this reversed pre-rRNA depletion (Supplemental Figure 6, A and B). We also tested the pyrimidine synthesis inhibitor vidofludimus. As expected, this drug depleted UTP and CTP, but had no effect on GTP or pre-rRNA abundance (Supplemental Figure 6, C and D). Thus, under these conditions, Pol I was more sensitive to depletion of GTP than other nucleotide triphosphates.

We next sought to raise GTP levels during IMPDH inhibition to test whether this would affect Pol I function. Protein synthesis hydrolyzes GTP for aminoacyl-tRNA loading, ribosome translocation, and termination. Cycloheximide inhibits translation elongation and suppresses GTP hydrolysis (45). Treating DMS53-CR cells with cycloheximide resulted in a dose-dependent increase in GTP and pre-rRNA abundance, with the highest dose completely reversing the effect of MPA on pre-rRNA levels (Figure 4, G and $\mathrm{H})$. Cycloheximide had no impact on pre-rRNA levels in DMS53CR cells unless GTP levels were depleted by MPA (Figure $4 \mathrm{H}$ ).

Pol I localization to the ribosomal DNA is sensitive to GTP abundance. Transcription of pre-rRNA requires assembly of the Pol I complex on the promoters of rDNA genes. To assess assembly of these complexes, we used ChIP and immunofluorescence to examine localization of RPA1, the largest Pol I subunit, to rDNA. In DMS53 cells, immunofluorescence revealed small nuclear puncta reflecting RPA1 localization to rDNA, but these puncta were much more prominent in DMS53-CR cells (Supplemental Figure 7C), consistent with the nucleolar prominence of cells derived from the variant SCLC subset (32). MPA had little effect on RPA1 localization in DMS53 cells, but markedly reduced the enhanced localization in DMS53-CR cells (Supplemental Figure 7, C and D). Fluorescence intensity was fully restored by cotreatment with guanosine (Figure 5, A and B). Although cycloheximide had no effect on RPA1 localization by itself, it reversed the effect of MPA to a similar extent as guanosine (Figure 5 , A and B). None of these treatments affected localization of RPB1, a subunit of Pol II (Figure 5A and Supplemental Figure 7C). RPA1 and RPB1 abundance was unaffected by MPA or guanosine (Supplemental Figure 7B). A ChIP-Seq analysis of RPA1 in human mammary epithelial cells (46) showed abundant binding to the rDNA promoter and the 18S, 5.8S, and $28 \mathrm{~S}$ coding regions (Supplemental Figure 7A). We therefore performed a comprehensive qPCR analysis in SCLC cells incorporating primer pairs to amplify all these regions. ChIP 
A

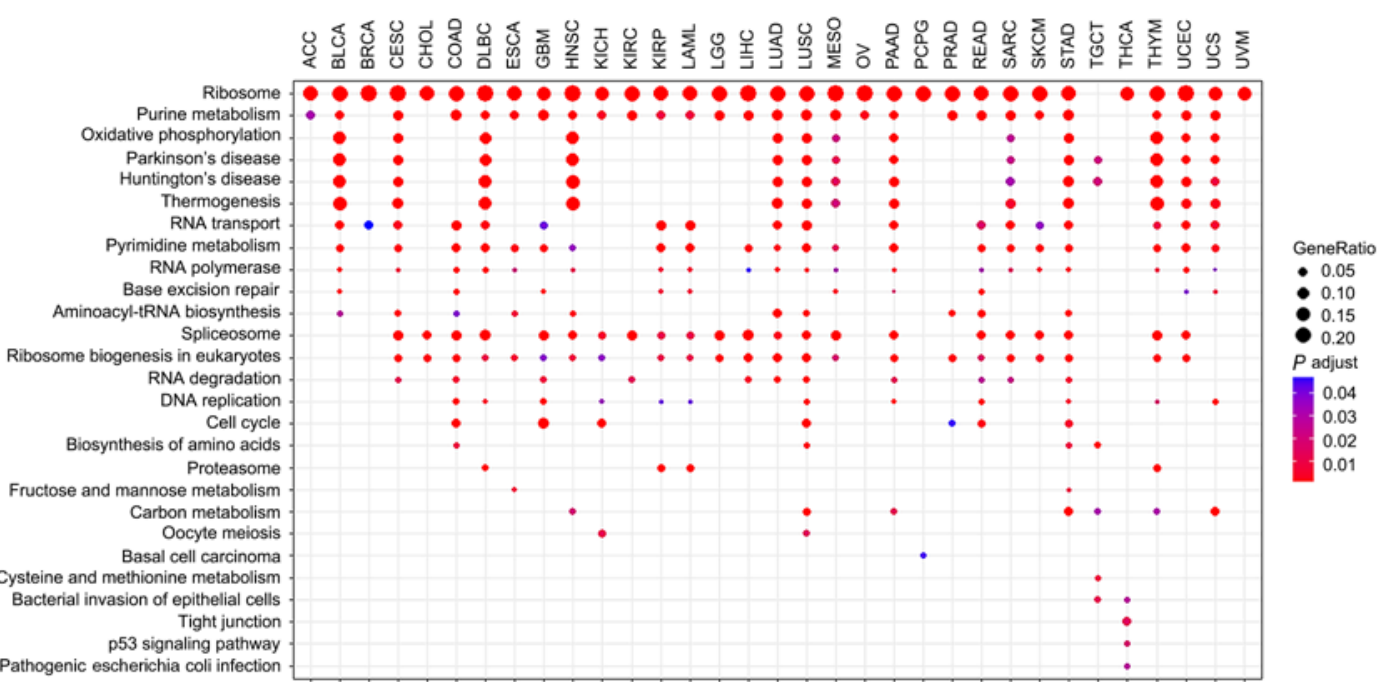

B

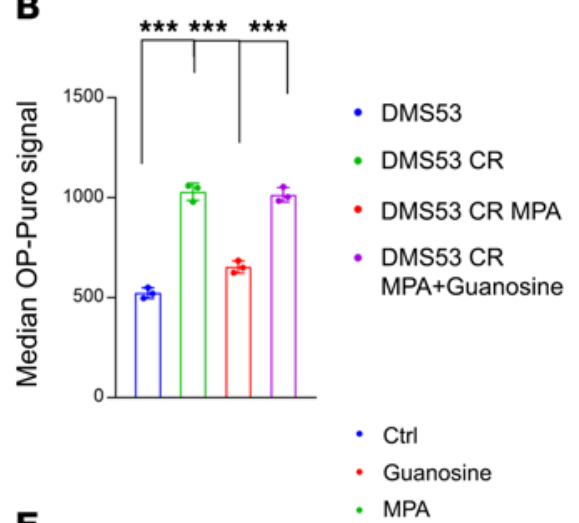

E

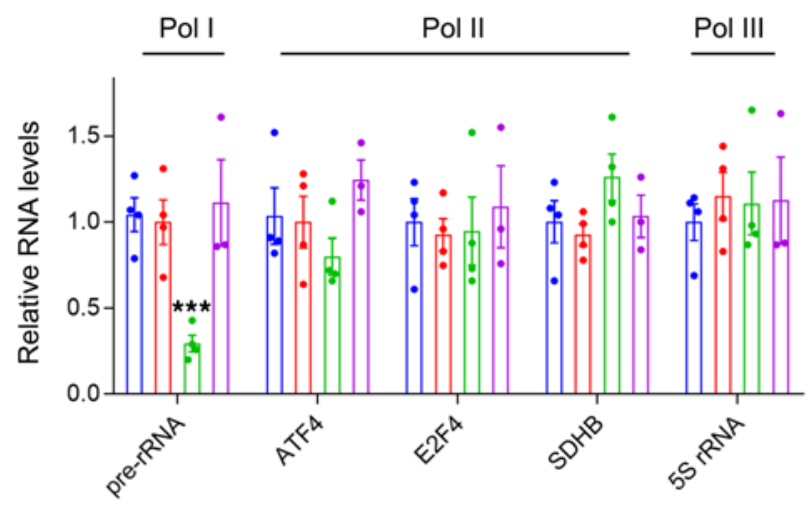

$\mathbf{G}$

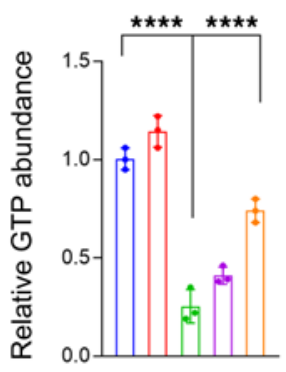

H
C $\quad \cdot$ Ctrl

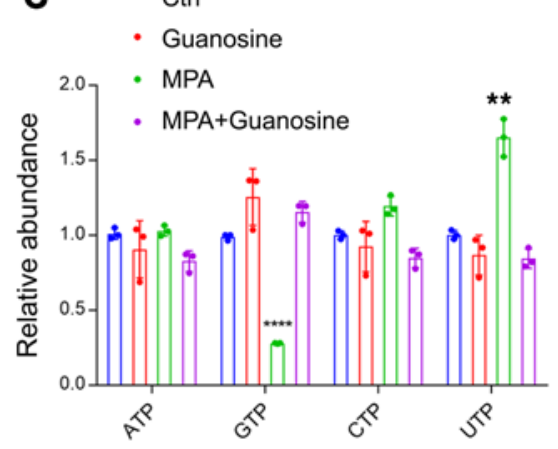

$\mathbf{F}$
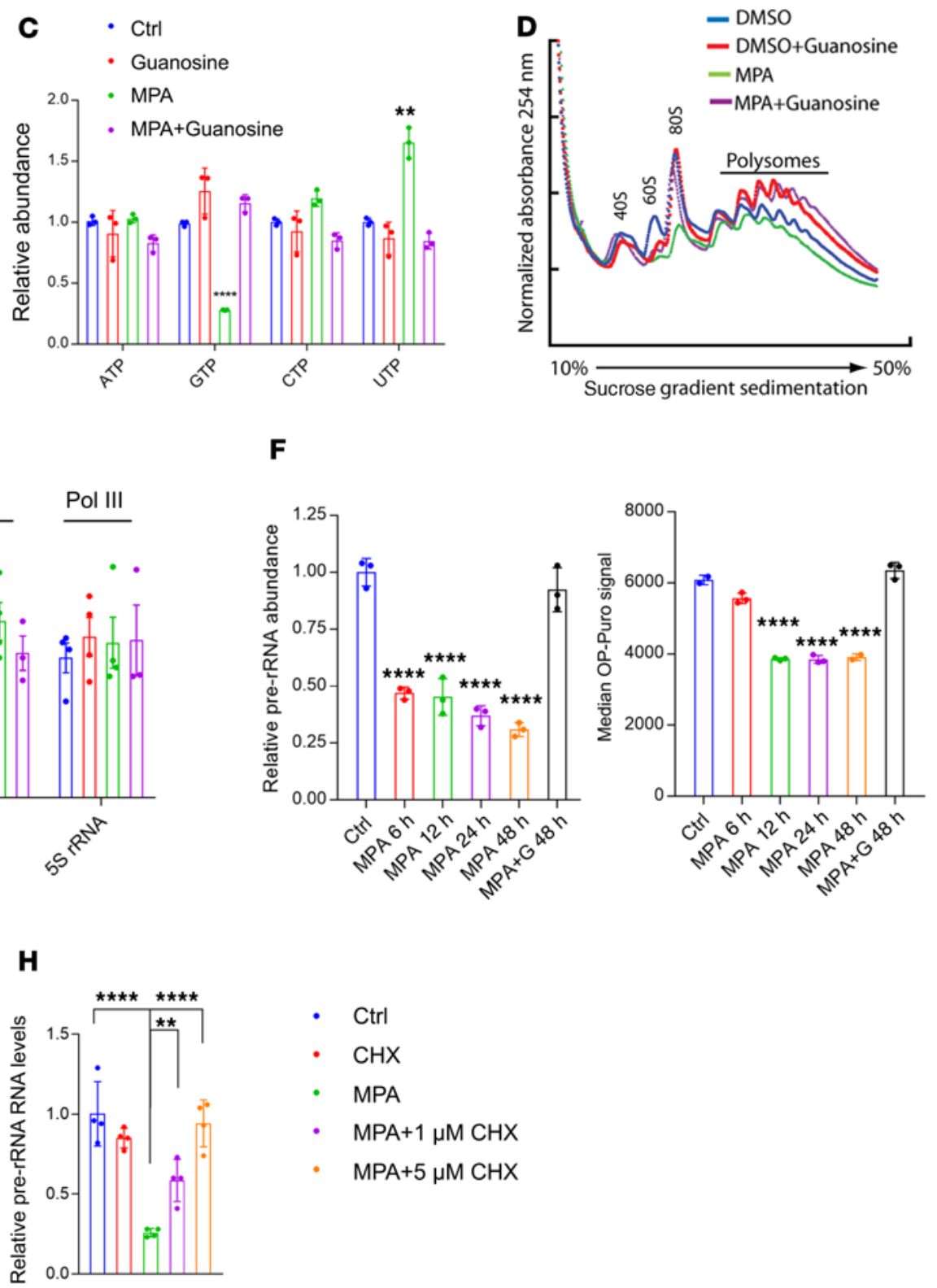

- Ctrl

- $\mathrm{CHX}$

- MPA

- MPA+1 $\mu \mathrm{M} \mathrm{CHX}$

- MPA+5 $\mu \mathrm{M}$ CHX 
Figure 4. Enhanced de novo GTP synthesis promotes Pol I activity in chemoresistant SCLC cells. (A) Gene sets associated with IMPDH2 mRNA across human cancers in the TCGA database. All KEGG gene sets were included in the analysis. (B) Median OP-Puro signal in DMS53 treatment-naive and chemoresistant cells treated with vehicle or $1 \mu \mathrm{M}$ MPA, with or without 20 $\mu \mathrm{M}$ guanosine for 12 hours. ${ }^{* *} P<0.001$. (C) ATP, GTP, CTP, and UTP levels in DMS53-CR treated with vehicle or $5 \mu \mathrm{M}$ MPA, with or without $10 \mu \mathrm{M}$ guanosine for 8 hours. ${ }^{* *} P<0.01$, ${ }^{* * *} P<0.0001$. (D) Ribosome abundance in DMS53-CR treated with vehicle, $1 \mu$ M MPA, with or without $20 \mu$ M guanosine for 48 hours. (E) Abundance of Pol I, II, or III transcripts in DMS53-CR cells treated with vehicle or $5 \mu \mathrm{M}$ MPA with or without $20 \mu \mathrm{M}$ guanosine for 8 hours. ${ }^{* *} P<0.001$. (F) Abundance of pre-rRNA and median OP-Puro signal in $\mathrm{H} 82$ treated with vehicle or $1 \mu \mathrm{M}$ MPA, with or without $10 \mu \mathrm{M}$ guanosine. ${ }^{* * *} P<0.0001$. (G and $\mathbf{H}$ ) Abundance of GTP and pre-rRNA in DMS53-CR treated with vehicle or $5 \mu \mathrm{M}$ MPA, with or without 1-5 $\mu \mathrm{M}$ cycloheximide for 6 hours. ${ }^{*} P<0.01,{ }^{* * * *} P<0.0001$. Data are shown as mean and SD (B, C, and $\mathbf{F}-\mathbf{H})$, mean and SEM (E). Statistical significance was assessed using 1-way ANOVA with Tukey's multiple-comparison test (B, C, and E-H). All experiments were repeated twice or more.

revealed much higher Pol I occupancy by RPA1 in DMS53-CR cells compared with treatment-naive DMS53 cells, but occupancy was essentially eliminated with MPA and rescued with guanosine (Figure 5, C-F). Pre-rRNA abundance was reduced by MPA in both DMS53 and DMS53-CR cells, although the effect was larger in DMS53-CR cells (Supplemental Figure 7E); in DMS53 cells, reduced pre-rRNA abundance in absence of marked changes in RPA1 localization may reflect GTP's role as a Pol I substrate. H82 cells responded to MPA similarly to DMS53-CR cells, with reduced Pol I occupancy on rDNA reversed by either cycloheximide or guanosine, and no effect on Pol II localization (Supplemental Figure 7, F and G).

To test whether MYC is sufficient to induce these effects, we used ASCL1 ${ }^{\text {hi }} /$ MYC $^{\text {lo }}$ H1436 cells expressing an empty vector or a doxycycline-inducible MYC. As expected, MYC increased ribosome abundance (Supplemental Figure 7I). It also generated large, intense RPA1 foci on immunofluorescence (Supplemental Figure $7 \mathrm{H}$ ), but MPA reduced intensity to the level of parental cells (Supplemental Figure 7, $\mathrm{H}$ and J). MPA reduced pre-rRNA levels in both cell lines, but the effect was more prominent in cells overexpressing MYC (Supplemental Figure 7K). Therefore, in cells with elevated MYC, GTP synthesis supported robust ribosome biogenesis in part by enabling Pol I localization to rDNA.

$M Y C$ regulates Pol I through a mechanism involving GTP synthesis, GPN1, and GPN3. Although GTP is a substrate for Pol I, its specific effect on Pol I localization prompted us to consider the involvement of GTP-binding proteins in this process. BioPlex 2.0 (47) predicted an interaction between RPA1 and GPN3 (Supplemental Figure 8A). This was interesting because GPN3, through a physical association with the related protein GPN1, associates with the Pol II complex and in some cells promotes assembly of functional Pol II in the nucleus (48-51). GPN1 and GPN3 belong to a family of GTPases with conserved GPN (glycine, proline, asparagine) and guanine nucleotidebinding domains $(48,52)$. By probing the pan-cancer TCGA database, we found that GPN1 is among the transcripts most positively correlated with GPN3 (Supplemental Figure 8B) and that both GPN1 and GPN3 are highly correlated with ribosome gene sets (Figure 6A).

We next explored the relationship between GPN1/GPN3 and MYC. In autochthonous SCLC GEMMs, tumors with transgenic
$M y c$ had high expression of Gpn1 and Gpn3 (Figure 6B). ChIP-Seq data from the MYC ${ }^{\text {hi }}$ human SCLC cell line H2171 (53) and from mouse SCLCs in GEMMs with transgenic Myc revealed MYC binding in GPN1 and GPN3 promoters (Supplemental Figure $8 \mathrm{C}$ ). Chemoresistant patient-derived xenografts (PDXs) with high $M Y C$ had elevated GPN1 and GPN3 mRNA relative to patient-matched, treatment-naive tumors with lower MYC (Supplemental Figure 2H). GPN1 and GPN3 were expressed at elevated levels in DMS53-CR cells and H1436-CR tumors relative to treatment-naive parental lines (Figure 6, C and D, and Supplemental Figure 8, D and E). Doxycycline-induced MYC expression in H1436 cells led to a dose-dependent increase GPN1, GPN3, and IMPDH2, indicating that MYC was sufficient to drive expression of GPN1 and GPN3 (Figure 6E). We also generated $\mathrm{H} 1436$ cells that constitutively overexpress MYC, N-MYC, or L-MYC, and found that all 3 increased the expression of GPN1, GPN3, and IMPDH2 (Supplemental Figure 8F). We note that PDXs derived from treatment-naive and relapsed SCLC (38) more prominently overexpressed MYC than either MYCN or $M Y C L$ in the relapsed state, emphasizing the importance of $M Y C$ in this context (Supplemental Figure 8G).

To examine the requirement for GPN1 and GPN3 in SCLC cells, CRISPR/Cas9 genome editing was used to create H82 cells (ASCL1 $1^{\mathrm{lo}} / \mathrm{Myc}^{\mathrm{hi}}$ ) null for each protein. Loss of either protein reduced protein synthesis and cell proliferation (Figure 6, F and G). Sequence alignment with other GTPases identified a highly conserved lysine in the GTP binding domain and glutamine in the GTP hydrolysis domain in GPN1 and GPN3 (Supplemental Figure 9A). Mutating this glutamine in the yeast GPN1 homolog Npa3 creates a constitutively GTP-bound mutant (50). After mutating these 2 residues in both GPN1 and GPN3, we generated an allelic series of MYC-tagged mutants in H82 cells (GTP-binding mutants: GPN1 K190E and GPN3 K175E; GTP hydrolysis mutants: GPN1 Q126L and GPN3 Q110L) for further analysis.

As expected, IP of GPN3-Myc pulled down GPN1 (Figure 6H). Both GPN1 and GPN3 bound to GTP agarose, and this interaction could be outcompeted with excess GTP (Figure 6I). To assess the affinity of GPN1 and GPN3 for GTP relative to more familiar GTPases, we performed a competition assay by using increasing concentrations of GTP to disrupt binding to GTP-agarose. For both GPN1 and GPN3, low concentrations of GTP (under $10 \mu \mathrm{M}$ ) disrupted binding to GTP-agarose, whereas much higher concentrations were required to disrupt RAS binding (Figure 6J). The GTP-binding mutations GPN1 K190E and GPN3 K175E abolished binding to GTP-agarose, but the GTP hydrolysis mutants GPN1 Q126L and GPN3 Q110L displayed persistent and somewhat enhanced binding (Figure 6I).

IP revealed binding of GPN1 and GPN3 to RPA1, and mutating the GTP binding domain inhibited these interactions (Figure 7, A and B). GPN3 deficiency markedly reduced both the intensity of RPA1 nuclear puncta and rDNA occupancy in DMS53-CR cells (Figure 7, C-F). Wild-type but not K175E-mutant GPN3 rescued these activities, indicating that GPN3's GTP-binding activity is required for maximal Pol I localization in these cells (Figure 7, C-F). Importantly, residual Pol I localization did not require GPN3, but GPN3 was required for the prominent nucleolar fluorescence and high levels of rDNA occupancy typical of the MYC ${ }^{\text {hi }}$ state.

Finally, we explored the relationship between these GTPases and drug sensitivities. GPN3 bound to RPA1 in both treatment-naive and 
A
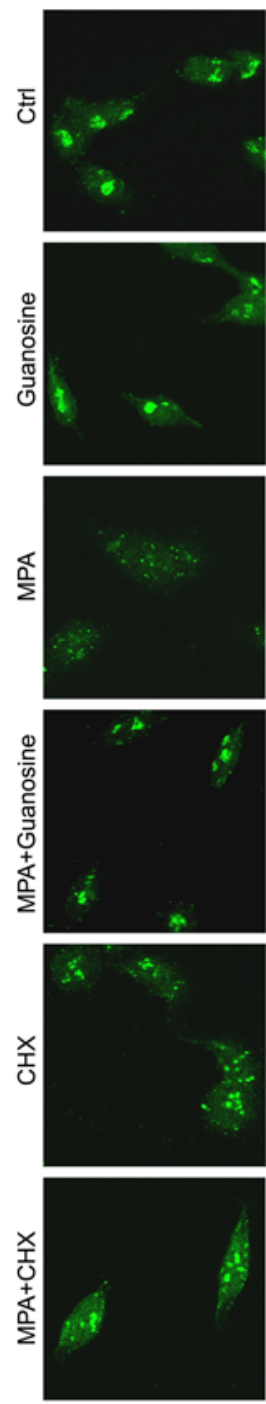

D
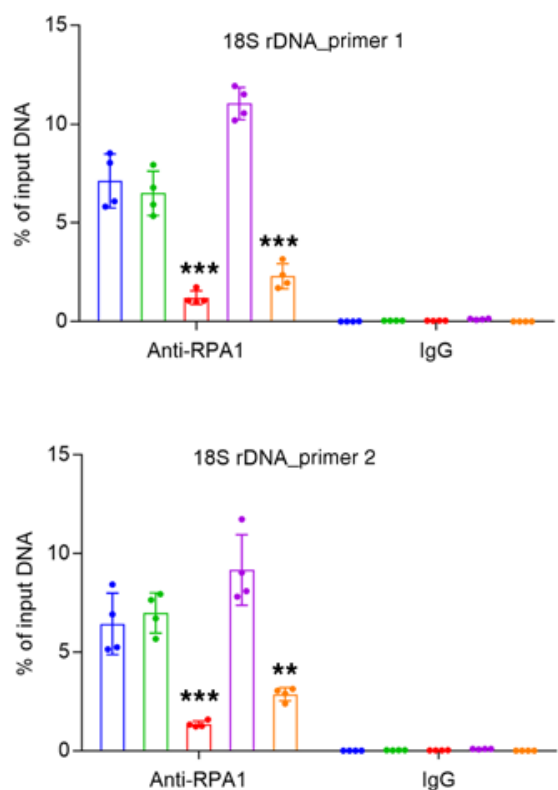

RPB1
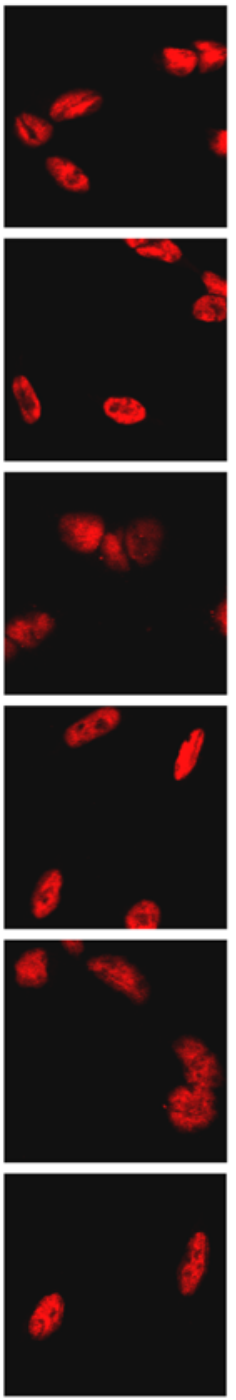

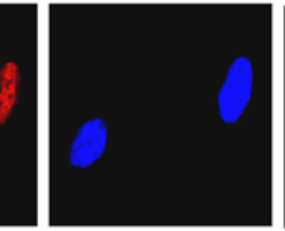

E
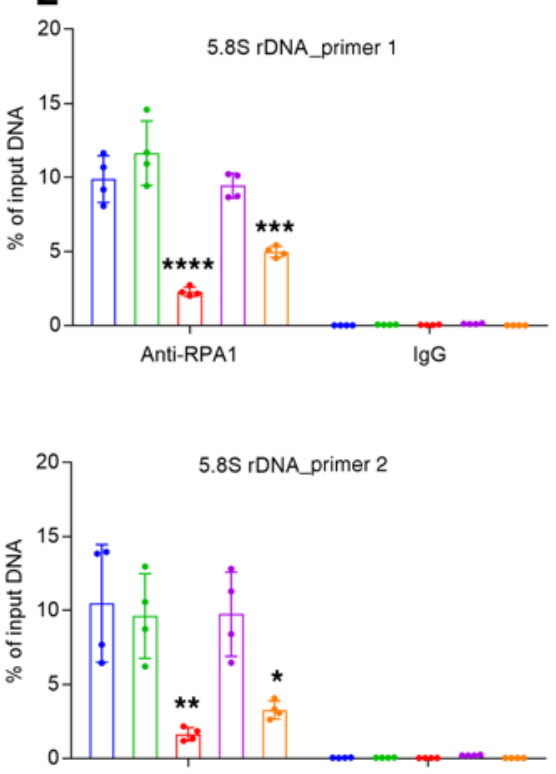

Anti-RPA1
Merge
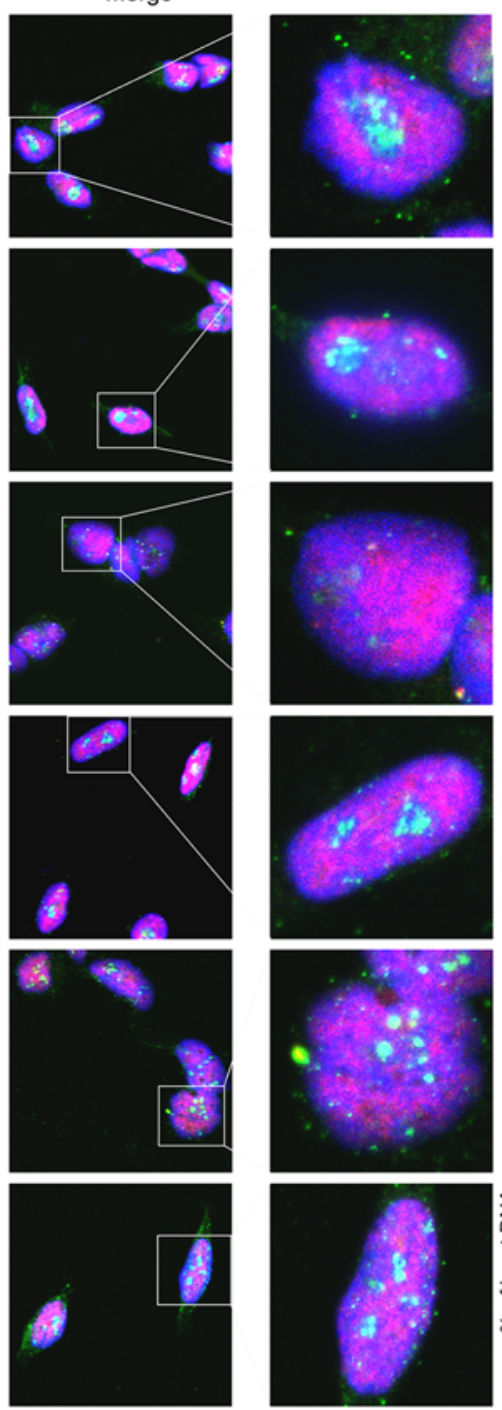

$\mathbf{F}$
B
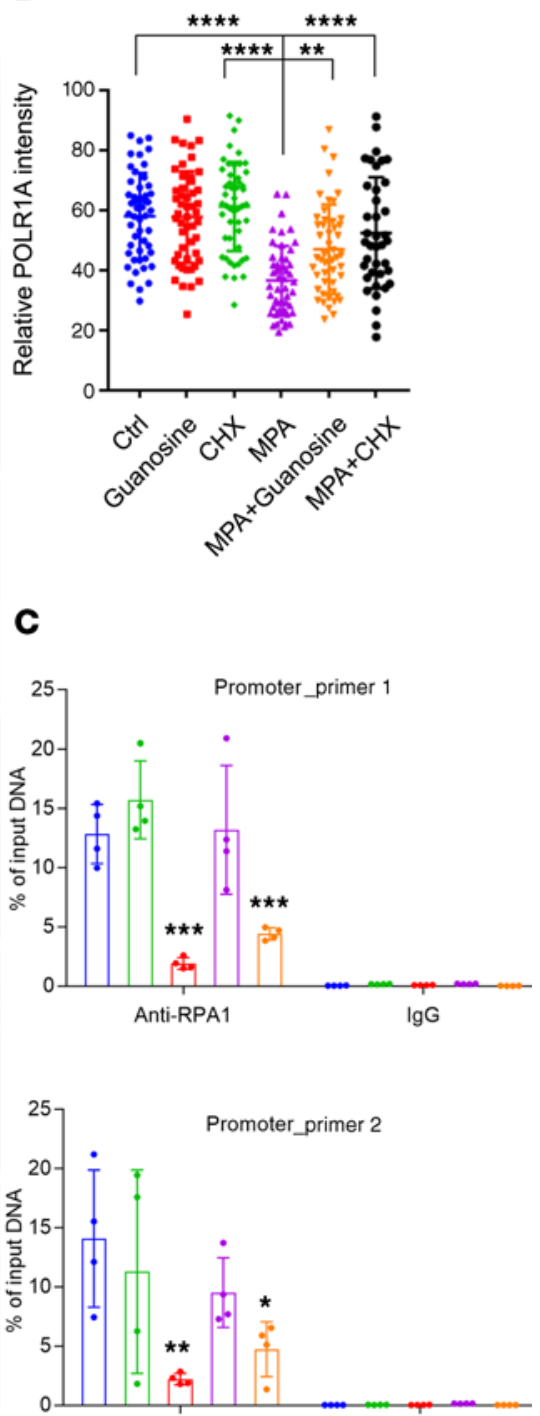

Anti-RPA1

$\lg G$
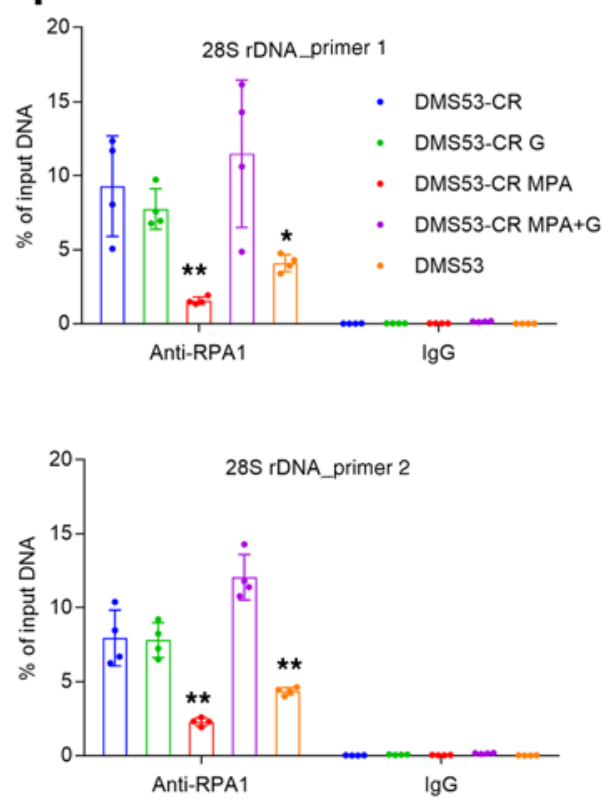
Figure 5. Pol I localization to the ribosomal DNA is sensitive to GTP abundance. (A) Localization of RPA1 and RPB1 in DMS53-CR cells treated with vehicle or MPA, with or without guanosine or cycloheximide for 8 hours. Nuclei are stained with DAPI (blue). Original magnification, 63x. (B) Nuclear RPA1 immunofluorescence signals for cells in A. 50-100 cells were quantified in each group. ${ }^{* *} P<0.01,{ }^{* * *} P<0.0001$. (C-F) qPCR for the rDNA promoter and $185,5.85$, and 285 coding regions after ChIP with an anti-RPA 1 antibody or IgG control. DMS53-CR cells were treated with MPA or vehicle, with or without guanosine for 12 hours. DMS53, the treatment-naive parental cell line of DMS53-CR, is included as a reference. Two independent primer pairs (P1, P2) were designed for each region. ${ }^{*} P<0.05,{ }^{* *} P<0.01,{ }^{* *} P<0.001$, ${ }^{* * *} P<0.0001$. Data are shown as mean and SD (B-F). Statistical significance was assessed using 1-way ANOVA with Tukey's multiple-comparison test (B-F). All experiments were repeated twice or more.

chemoresistant SCLC (Supplemental Figure 9B), and neither GPN3 loss nor reconstitution of GPN3-deficient cells with a GTP-binding mutant of GPN3 resensitized chemoresistant cells to platinum (Supplemental Figure 9, C and D). However, mutants that could bind but not hydrolyze GTP (GPN1 Q126L and GPN3 Q110L) displayed marked enhancement of RPA1 binding compared with wild-type isoforms (Figure 7A). More importantly, GPN3 Q110L mitigated the effect of MPA on nucleolar Pol I fluorescence (Figure 8A and Supplemental Figure 9, E and F) and partially blocked MPA's effect on pre-rRNA abundance and protein synthesis relative to wild-type GPN3 (Figure 8, B and C). Expressing either GPN1 Q126L or GPN3 Q110L also allowed these cells to partially resist MPA relative to cells expressing no or wild-type GPN1 and GPN3 (Figure 8, D and E, and Supplemental Figure 9, F and G). These data indicate that MPA's effect on growth suppression in MYC ${ }^{\text {hi }}$ SCLC cells occurred at least partially through GTP-dependent Pol I assembly.

\section{Discussion}

A fundamental question in cell growth regulation is how cells balance myriad programs to culminate in an integrated growth response. MYC family members induce multiple transcriptional programs necessary for growth, but we have little insight into how these programs are synchronized to avoid, for example, unnecessary ribosome assembly when metabolism is inadequate to support growth. MYC stimulates ribosome biogenesis, including transcription of pre-rRNA and genes for ribosomal proteins $(20,54)$. Ribosome biogenesis is crucial for cancer initiation and progression, and MYC's ability to stimulate ribosome biogenesis is required for its oncogenic function (55-57).

The immense amount of energy and biosynthetic precursors required to synthesize ribosomes suggests that MYC's ability to stimulate ribosome biogenesis is linked to its metabolic functions. Energetic stress caused by glucose deprivation results in transcriptional silencing from rDNA, providing one mechanism by which cells reduce ribosome biogenesis in response to metabolic stress (58). MYC-stimulated purine biosynthetic genes like IMPDH 2 are coexpressed with ribosome genes and are required for cells with oncogenic MYC to carry out maximal rates of protein synthesis and growth. GTP, the end product of the IMPDH pathway, acts as a gate for Pol I localization to rDNA and synthesis of pre-rRNAs (Figure $8 \mathrm{~F}$ ). This coordination between nucleotide and protein synthesis is reminiscent of MYC's effects on phosphoribosyl-pyrophosphate synthetase-2 (PRPS2), another nucleotide biosynthetic enzyme (59). MYC stimulates Prps2 transcription, but synthesis of the protein requires that eIF4e, a translation initiation factor and MYC transcriptional target, bind to the Prps $25^{\prime}$-UTR.

Although MYC regulates many aspects of nucleotide metabolism, the mechanism linking de novo nucleotide synthesis to Pol I is specific to GTP. Inhibiting de novo GTP synthesis reduced Pol I localization to rDNA and pre-rRNA abundance, and these defects were reversed by providing the GTP precursor guanosine, which does not require the de novo synthesis pathway. Depleting the other RNA precursors, ATP, CTP, and UTP, did not acutely suppress pre-rRNA abundance, emphasizing that GTP's role in regulating Pol I is not simply related to its use as a Pol I substrate. Gating Pol I function to GTP abundance positions this metabolite as essential to the growth program regulated by MYC.

It is interesting that GTP rather than other nucleotides is so central to ribosome biogenesis. Perhaps this is because protein synthesis imposes a high demand for GTP, with multiple steps of this process powered by GTP hydrolysis. GTP also better integrates the overall metabolic preparedness for growth than other nucleotides. GTP and ATP are synthesized from the common precursor IMP. But the terminal step in GTP synthesis requires expenditure of 2 high-energy phosphates, converting ATP to AMP $+\mathrm{PP}_{\mathrm{i}}$, and replacement of a carbonyl group with the amide nitrogen of glutamine. ATP synthesis, in contrast, requires only a single high-energy phosphate (from GTP) and nitrogen donation from aspartate.

We identified GPN1 and GPN3 as RPA1-binding proteins required to maximize Pol I localization to rDNA, pre-rRNA transcription, and cell growth. Both proteins are MYC targets whose expression is activated during acquired chemoresistance in SCLC. Although these proteins did not influence chemosensitivity in our models, they were required for chemoresistant cells to achieve high rates of Pol I function and proliferation driven by MYC. Because L-MYC and N-MYC also increased GPN1/3 expression, it is possible that chemoresistant SCLCs with increased expression of these other MYC family members also gain dependence on this mechanism of Pol I regulation. We speculate that MYC's role in stimulating ribosome biogenesis underlies the selective IMPDH dependence observed in our models. Details are emerging about the specific functions of GPN1 and GPN3, but the yeast homologs are nonredundant and structure-function studies suggest that GTP-bound GPN1 acts as a chaperone for nascent Pol II subunits, facilitating their assembly into Pol II complexes $(50,60)$. It remains to be seen precisely how GPN proteins support Pol I assembly, but GTP binding is required for both GPN1 and GPN3 to promote Pol I localization to the rDNA in the models we studied.

GTP is required for multiple steps of ribosome biogenesis and protein synthesis. This makes it difficult to know the extent to which altered Pol I function contributes to growth suppression during IMPDH inhibition, as opposed to other GTP-dependent processes. Our analysis of GPN1 and GPN3 adds clarity to this issue. Mutants defective in GTP hydrolysis showed increased Pol I binding. These mutants did not enhance Pol I nucleolar localization in cells with sufficient GTP, but they mitigated MPA's effects on Pol I localization, pre-rRNA abundance, protein synthesis, and growth. As expected, the protection was only partial because it did not rescue the many downstream effects of GTP on RNA and protein synthesis. But the 
A

GPN3 correlated gene sets in pan cancer

GPN1 correlated gene sets in pan cance
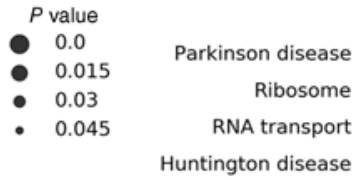

\section{-}

Non-alcoholic fatty liver disease (NAFLD)

Alzheimer disease -

Oxidative phosphorylation -

Spliceosome -

Progesterone-mediated oocyte maturation

Oocyte meiosis -

Thermogenesis

Nucleotide excision repair

Proteasome

Base excision repair

Cell cycle

Ubiquitin mediated proteolysis -

DNA replication -

Cellular senescence -

Human T-cell leukemia virus 1 infection -

Mismatch repair -

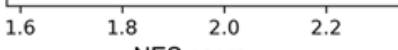

B
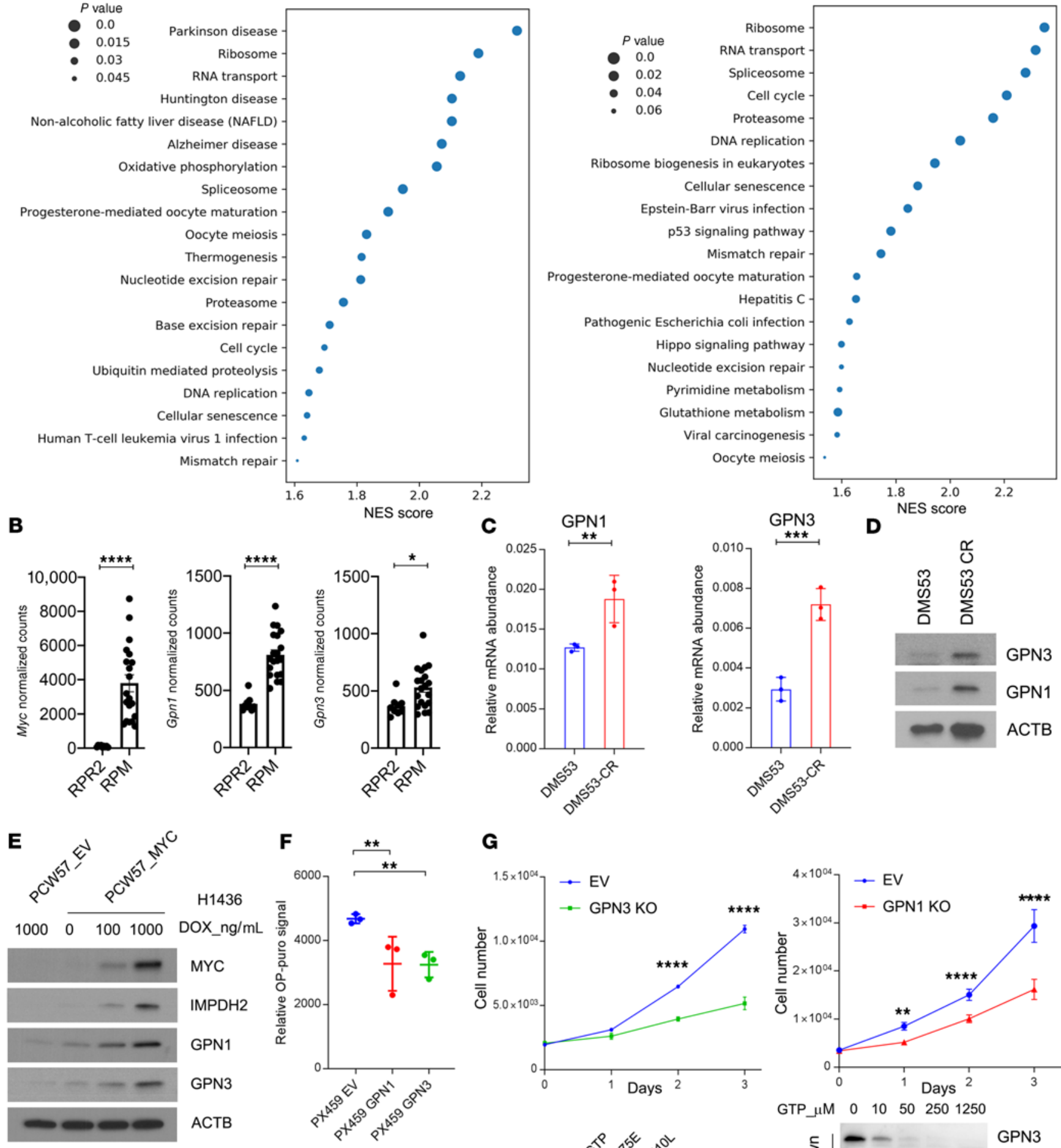

G
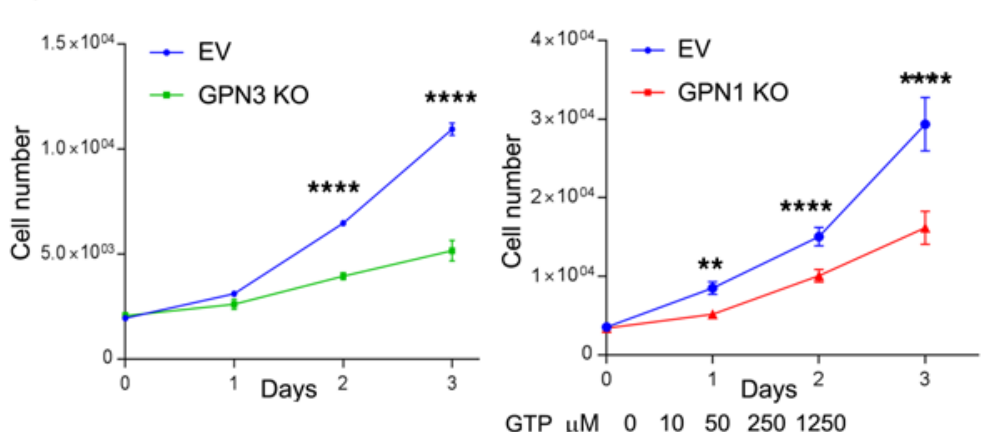

H
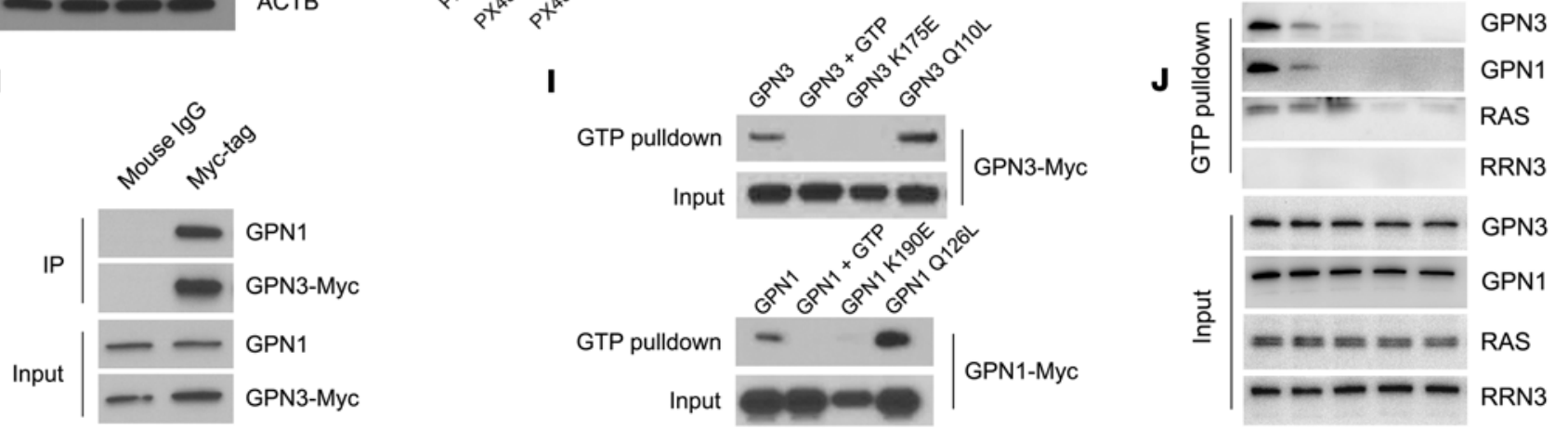
Figure 6. GTP abundance regulates Pol I function in Myc ${ }^{\text {hi }}$ cells in part through GPN1 and GPN3. (A) Gene sets correlated with GPN3 or GPN1 mRNA from 9,879 tumors in the pan-cancer TCGA database. Gene set enrichment analysis was performed on the top $2 \%$ of genes positively correlated with GPN3 or GPN1. (B) mRNA abundance of Myc, Gpn1, and Gpn3 in SCLCs obtained from genetically engineered mouse models with mutant $\operatorname{Trp53}, R b 1$, and $R b / 2$ (RPR2) and tumors with mutant $\operatorname{Trp} 53$ and $R b 1$ plus transgenic $M y c^{T 58 A}$ (RPM). ${ }^{*} P<0.05,{ }^{* * * *} P<0.0001$. (C) GPN1 and GPN3 mRNA abundance in DMS53 and DMS53-CR. ${ }^{* *} P<0.01,{ }^{* *} P<0.001$. (D) Abundance of GPN1 and GPN3 in DMS53 and DMS53-CR. (E) Abundance of MYC, IMPDH2, GPN1, and GPN3 in H1436 cells expressing dox-inducible empty vector (EV) or MYC treated with doxycycline at the indicated doses for 6 days. (F) OP-Puro signal in pooled $\mathrm{H} 82$ cells expressing an EV or with CRISPR/Cas9-mediated knockout of GPN3 or GPN1. ${ }^{* *} P<0.01$. (G) Proliferation of $\mathrm{H} 82$ pools shown in $\mathbf{F} .{ }^{* *} P<0.01$, ${ }^{* * *} P<0.0001$. (H) Immunoprecipitation with anti-Myc-tag or mouse IgG followed by Western blot for GPN1 or Myc in H82 cells with CRISPR/Cas9-mediated GPN3 knockout and reexpression of wild-type GPN3. (I) GTP pulldown for wild-type or mutant isoforms of GPN3-Myc or GPN1-Myc. GTP was used to compete for binding of GPN1/3 to GTP-agarose beads. (J) GTP pulldown for GPN3, GPN1, RAS, or RRN3 using H82 lysates with increasing concentrations of GTP to compete for binding to GTP-agarose beads. Data are shown as mean and SD (B, C, $\mathbf{F}$, and $\mathbf{G})$. Statistical significance was assessed using a 2-tailed Student's $t$ test (B and $\mathbf{C}$ ), 1-way ANOVA with Tukey's multiple-comparison test ( $\mathbf{F}$ and C). All experiments were repeated twice or more.

protective effect of the mutants establishes that Pol I localization is involved in IMPDH dependence in MYC ${ }^{\text {hi }}$ cells. We emphasize that additional GTP-binding proteins also participate in Pol I function in cells with oncogenic MYC. We noted a high concordance between the requirement for IMPDH2 and for RRN3, which encodes the key Pol I assembly factor TIF-1A. TIF-1A binds GTP, and GTP depletion in T cells reduces Pol I activity by impairing TIF-1A function (61).

Although $21 \%$ of human cancers have MYC amplifications, we lack specific therapies for these tumors. Large-scale screenings of SCLC cell lines have reported variable effects of MYC on drug sensitivity, with one study finding enhanced sensitivity to Aurora kinase inhibitors in $\mathrm{MYC}^{\text {hi }}$ cells; this correlation was confirmed in a genetic mouse model of Mychi SCLC $(29,62,63)$. MYC's metabolic effectors have been studied as therapeutic targets in other forms of cancer. MYC regulates uptake of glucose and glutamine and allocation of these nutrients into pathways that support cell survival and proliferation. FX11 inhibits LDHA, a MYC transcriptional target, and suppresses xenograft growth in mice (64). BPTES inhibits glutaminase, which is highly expressed in cells with oncogenic MYC, and suppresses tumorigenesis in a genetically modified mouse model of MYC-driven renal tumors (65). De novo GTP synthesis requires contributions from many pathways considered to be independent metabolic liabilities, including glucose/glutamine metabolism, the one-carbon/folate cycle, and serine/glycine synthesis.

Heterologous MYC expression is sufficient to induce IMPDH dependence (31), and we report multiple settings where MYC drove sensitivity to IMPDH inhibitors. These include treatment-naive tumors with oncogenic MYC and cells that activated MYC expression during the development of chemoresistance in patients, mice, and culture. This is notable because the multidrug resistance that emerges in relapsed SCLC renders these tumors intractable. MYC activation is also linked to resistance to drugs targeting other oncogenic drivers, including PI3K, c-Met, and BRAF/MEK $(36,66,67)$. The common occurrence of MYC activation in relapsed cancer raises the possibility of broad clinical utility of IMPDH inhibitors and perhaps other drugs targeting ribosome biogenesis and protein synthesis. It is important to note that despite mizoribine's immunosuppressive properties, it reduces tumor growth in immunocompetent mice as shown here and in other models $(31,68)$. It will be interesting to determine whether IMPDH inhibitors during the initial phase of SCLC treatment with cytotoxic agents can prolong the remission state by delaying the emergence of chemoresistant tumors with elevated MYC expression. Altogether, the findings describe a target in chemoresistant $\mathrm{MYC}^{\mathrm{hi}}$ SCLC (IMPDH), clinically available drugs (mizoribine, MPA), and a potentially novel mechanism of action (GTP linking the metabolic and ribosomal outputs of oncogenic MYC).

\section{Methods}

Cell lines. Cells were cultured in RPMI 1640 medium (Sigma-Aldrich, R8758) supplemented with 10\% FBS (Gemini Bio-Products, 100-106) and penicillin/streptomycin at $37^{\circ} \mathrm{C}$ in a humidified atmosphere containing $5 \%$ $\mathrm{CO}_{2}$. DMS53, DMS53-CR, H1048, H1048-ECR, 3151T1, and 3151T1-ECR cells were provided by T. Oliver (University of Utah, Huntsman Cancer Institute). H82 and H1436 cells were obtained from the Hamon Cancer Center (University of Texas Southwestern Medical Center, Dallas, Texas, USA). All cells were DNA fingerprinted by PowerPlex (69) and verified as mycoplasma free with e-Myco kit (Bulldog Bio, 2523348).

Mouse studies. SCLC cells were suspended in a 1:1 mixture of Matrigel (BD Biosciences, 356237) and RPMI 1640 mixture, then $0.5 \times 10^{6}$ to $2 \times 10^{6}$ cells were s.c. implanted into 6-8-week-old NSG mice (the Jackson Laboratory, 005557). Mice were randomized after injection; $100 \mathrm{mg} / \mathrm{kg}$ mizoribine (Sigma-Aldrich, M3047) in saline or saline alone was i.p. injected every other day when tumors were palpable. Tumor size was measured using calipers and calculated by short (a) and long (b) diameters (volume $=a^{2} b / 2$ ).

For enzymatic tumor disaggregation and xenograft passaging, tumors were dissected, rinsed in sterile HBSS, and fractions were flash-frozen in liquid nitrogen and stored at $-80^{\circ} \mathrm{C}$ for molecular assays. The remaining tissue was finely minced with a scalpel, followed by enzymatic digestion in $200 \mathrm{U} / \mathrm{mL}$ collagenase IV (StemCell, 07426), $50 \mathrm{U} / \mathrm{mL}$ DNase II (Sigma-Aldrich, D4527), and $5 \mathrm{mM} \mathrm{CaCl}_{2}$ in $10 \mathrm{~mL} \mathrm{HBSS}$ for 20 minutes at $37^{\circ} \mathrm{C}$. Disaggregated cells were filtered through a $40 \mu \mathrm{m}$ cell strainer, washed twice with RPMI plus 10\% FBS to terminate digestion, and resuspended in serum-free RPMI, $1 \%$ penicillin/streptomycin (Sigma-Aldrich, P0781), and 25\% high-protein Matrigel (Corning, 354248) on ice for reinjection. Remaining cells were cryopreserved in FBS plus 10\% DMSO. All procedures were performed in sterile conditions unless specified.

Survival studies in LAP-MYC mice were performed as described (40). LAP-MYC mice were provided by H. Zhu (Children's Medical Center Research Institute, University of Texas Southwestern Medical Center). MYC overexpression was induced after birth, and mizoribine treatment started on day 26 when $5 \%$ of the liver was occupied by tumor. Mizoribine or saline was administered by i.p. injection from day 26 until the end of the experiment.

Primary SCLC tumor analysis. Primary SCLC specimens were collected during surgical lobectomy or pneumonectomy from treatmentnaive patients, then frozen and later subjected to protein and metabolite extraction. Samples from different centers were shipped on dry ice and processed at Tianjin Medical College. Four independent fractions of approximately $10 \mathrm{mg}$ were collected from each tumor specimen. Three 
A
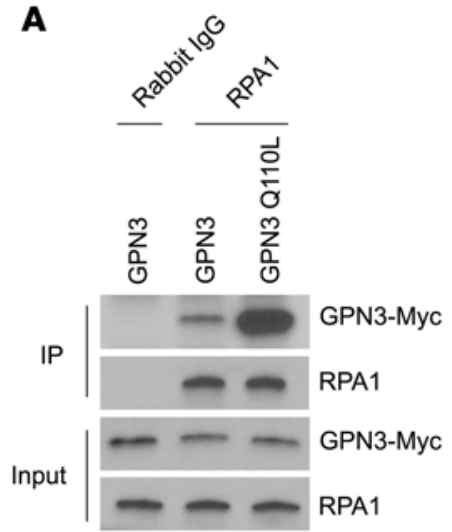

C

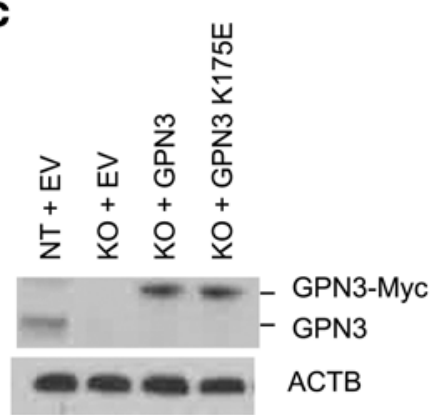

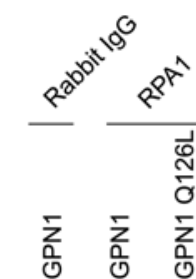

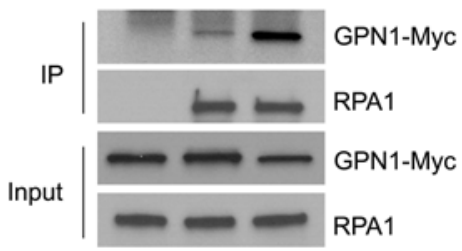

B

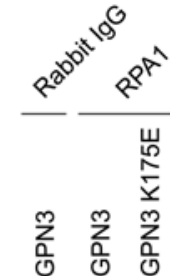

IP

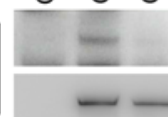

Input

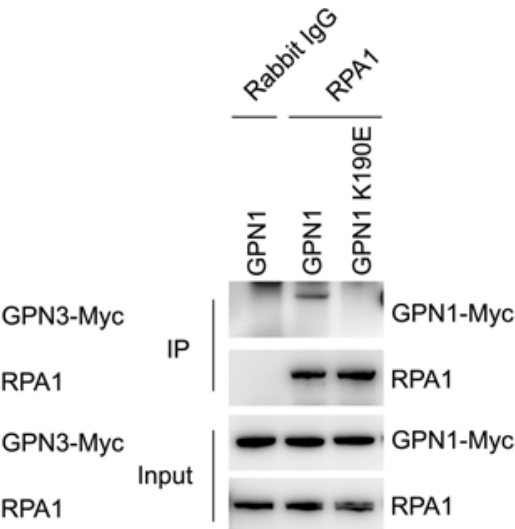

E
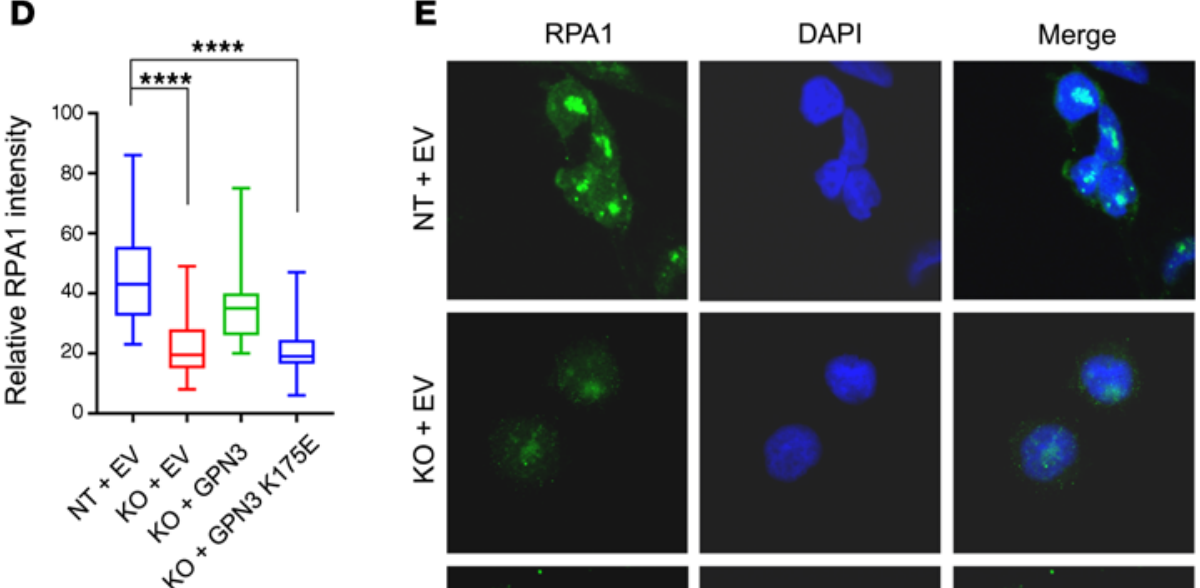

$\mathbf{F}$
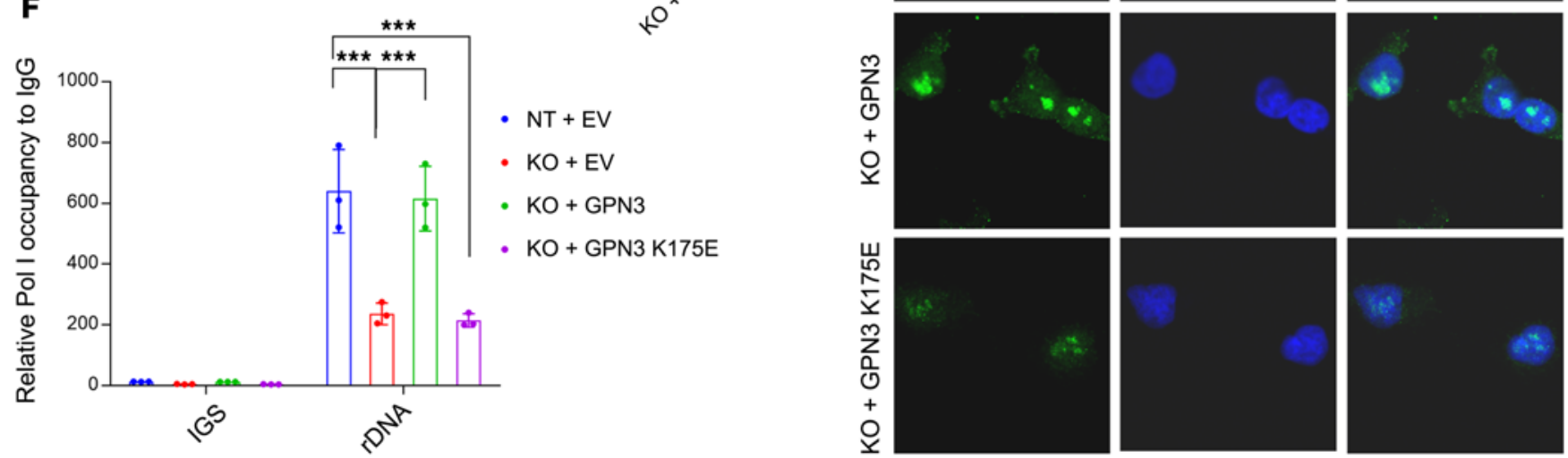

Figure 7. GTP abundance regulates Pol I function in Myc cells in part through GPN1 and GPN3. (A and B) Immunoprecipitation with anti-RPA1 or rabbit IgG followed by Western blot for RPA1, GPN3-Myc, or GPN1-Myc in H82 cells with CRISPR/Cas9-mediated knockout of GPN3 or GPN1 followed by reexpression of wild-type or mutant GPN3 or GPN1. (C) Abundance of native GPN3 and Myc-tagged GPN3 in DMS53-CR cells with CRISPR/Cas9-mediated GPN3 knockout and reexpression of empty vector (EV), wild-type, or mutant GPN3. KO, cells functionally null for GPN3; NT, nontargeting guide RNA. (D and E) Nuclear RPA1 immunofluorescence and sample images of cells from $\mathbf{C}$. ${ }^{* * *} P<0.0001$. Original magnification, $63 \times$. (F) qPCR for rDNA promoter and ICS sequences after ChIP with anti-RPA1 antibody or IgG control in cells from C. Data are ChIP enrichment with anti-RPA1 relative to lgG control. Data are shown as mean and SD (F). Statistical significance was assessed using 1-way ANOVA with Tukey's multiple-comparison test ( $\mathbf{D}$ and $\mathbf{F}$ ). All experiments were repeated twice or more.

fractions were homogenized in $1 \mathrm{~mL}$ ice-cold $80 \%$ methanol and 1 was homogenized in $500 \mu \mathrm{L}$ ice-cold RIPA buffer supplemented with protease inhibitors. Extracts were subjected to 3 freeze-thaw cycles between liquid nitrogen to $37^{\circ} \mathrm{C}$, then centrifuged at $14,000 \mathrm{~g}$ for 10 minutes at $4^{\circ} \mathrm{C}$ to remove debris. Metabolites from the supernatant of the $80 \%$ methanol extracts were evaporated in a SpeedVac for 6 hours and stored at $-80^{\circ} \mathrm{C}$. Protein lysates from the RIPA extraction were mixed with SDS-sample buffer and incubated at $95^{\circ} \mathrm{C}$ for 10 minutes, then stored at $-80^{\circ} \mathrm{C}$. To classify tumors for MYC expression, the Western blot in Figure $1 \mathrm{~B}$ was analyzed with Image (NIH) to normalize MYC signal to ACTB. Tumors with a relative intensity over 1000 were considered MYC ${ }^{\text {hi. }}$.

Metabolomics. Metabolites were reconstituted in $100 \mu \mathrm{L}$ of $0.03 \%$ formic acid in analytical grade water, vortexed, and centrifuged to remove insoluble material. Next, $20 \mu \mathrm{L}$ supernatant was subjected to targeted metabolomics analysis on an AB SCIEX QTRAP 5500 LC/ triple quadrupole MS (Applied Biosystems SCIEX) as described (70). 
A

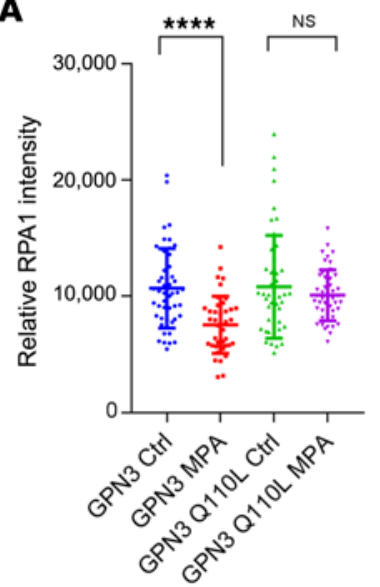

D

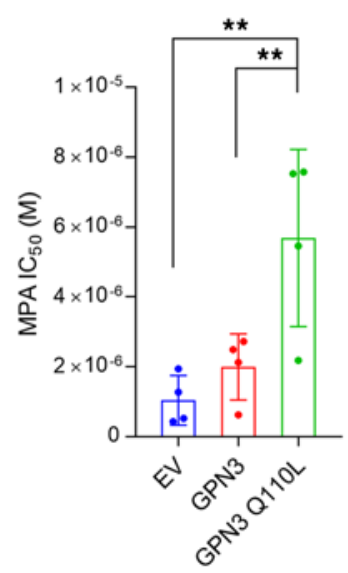

B

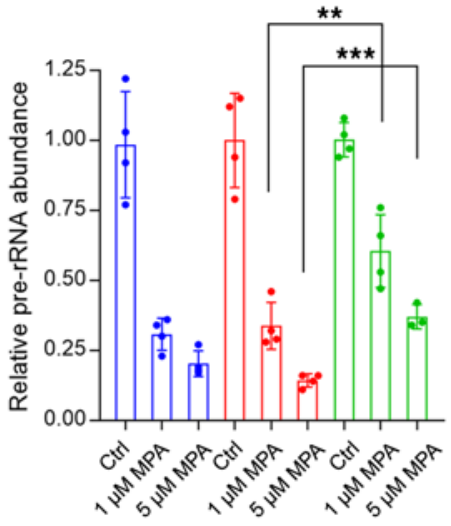

C

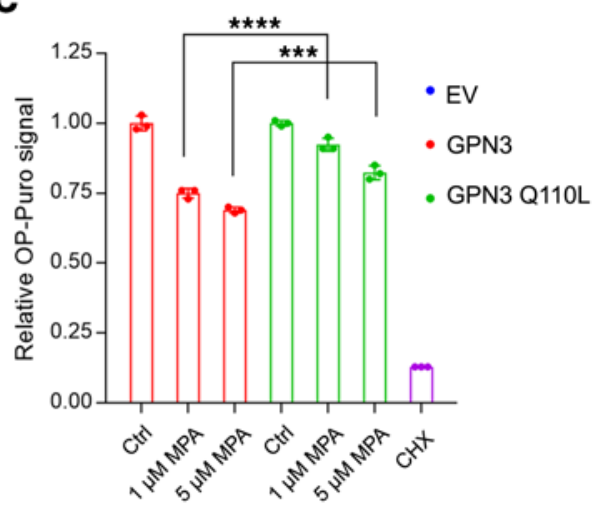

$\mathbf{E}$

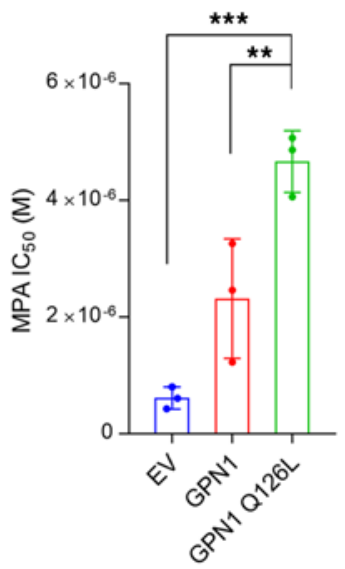

$\mathbf{F}$

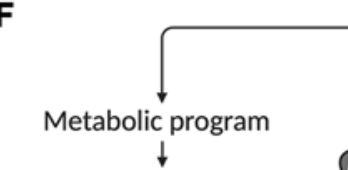

MYC
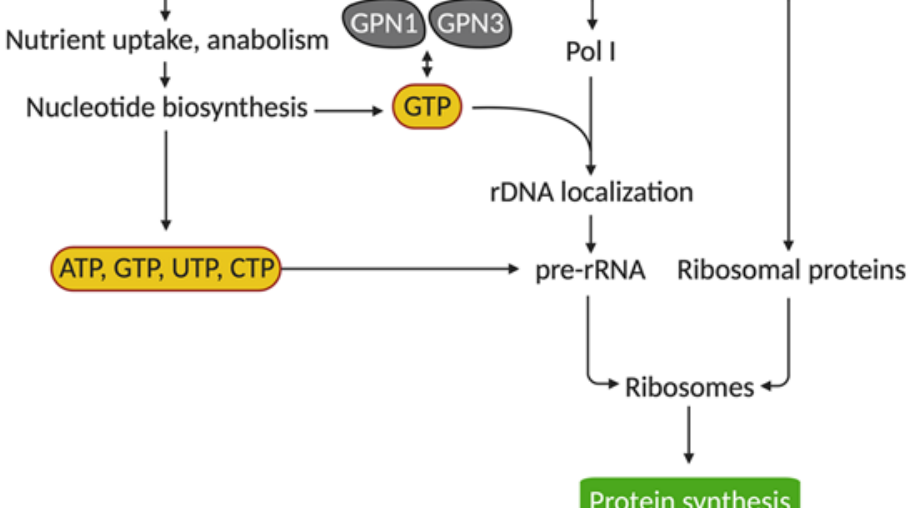

Figure 8. GTP abundance regulates Pol I function in Myc ${ }^{\text {hi }}$ cells in part through GPN1 and GPN3. (A) Nuclear RPA1 immunofluorescence signal in H82 cells with CRISPR/Cas9-mediated GPN3 knockout and reexpression of wild-type or mutant GPN3, treated with $1 \mu \mathrm{M}$ MPA or vehicle for 12 hours. ${ }^{* * *} P<0.001$, NS, not significant. (B) Abundance of pre-rRNA in H82 cells with CRISPR/Cas9-mediated GPN3 knockout and reexpression of wild-type or mutant GPN3, treated with 0,1 , or $5 \mu \mathrm{M}$ MPA for 8 hours. ${ }^{* *} P<0.01,{ }^{* *} P<0.001$. (C) OP-Puro signal in H82 cells with CRISPR/Cas9-mediated GPN3 knockout and reexpression of wild-type or mutant GPN3, treated with 0,1 , or $5 \mu \mathrm{M}$ MPA for 24 hours. A 30-minute cycloheximide treatment was used as a positive control. ${ }^{* * *} P<0.001$, ${ }^{* * * *} P<0.0001$. ( $\mathbf{D}$ and $\left.\mathbf{E}\right) \mathrm{MPA}_{\mathrm{IC}}$ in GPN3- or GPN1-deficient H82 cells reconstituted with empty vector (EV), wild-type, or mutant GPN3 or GPN1. ${ }^{* *} P<0.01$, ${ }^{* * *} P<0.001$. (F) GTP functions as a metabolic gate for Pol I function and ribosome biogenesis in cells with oncogenic MYC. Data are shown as mean and SD (A-E). Statistical significance was assessed using 1-way ANOVA with Tukey's multiple-comparison test (A-E). All experiments were repeated twice or more.

Chromatogram review and peak area integration were performed using MultiQuant (version 2.1, Applied Biosystems SCIEX). The peak area for each detected metabolite was normalized against the total ion count of each sample. Normalized peak areas were mean-centered and unit-variance scaled, then evaluated by principal component analysis to visualize clustering and detect outliers using SIMCA-P (version 13.0.1, Umetrics). Partial least-squares discriminant analysis and variable importance in projection analysis, as well as pathway enrichment analysis, were done using Metaboanalyst 3.0 (71).

${ }^{15} \mathrm{~N}$-glutamine and ${ }^{13} \mathrm{C}$-glucose labeling. Cells were incubated in RPMI 1640 media supplemented with 10\% dialyzed FBS (Gemini Bio-Products, 100-108) containing $0.3 \mathrm{mg} / \mathrm{mL}$ [amide $-{ }^{15} \mathrm{~N}$ ]glutamine or $2 \mathrm{mg} / \mathrm{mL}\left[\mathrm{U}^{13} \mathrm{C}\right.$ ]glucose for the indicated duration, washed with icecold saline, quenched with $80 \%$ methanol, and subjected to 3 freezethaw cycles. The debris was pelleted by centrifugation at $4^{\circ} \mathrm{C}$ and the supernatant was collected and evaporated to dryness using a SpeedVac concentrator. Metabolites were reconstituted in $50 \mu \mathrm{L}$ of $0.03 \%$ formic acid in analytical grade water, vortexed, and centrifuged to remove insoluble material. Next, $10 \mu \mathrm{L}$ supernatant was analyzed as described previously with modifications using an AB QTRAP 5500 LC/triple quadrupole MS (Applied Biosystems SCIEX) (70). The modifications were as follows: gradient program: 0-1 minute, $1 \% \mathrm{~B} ; 1-4$ minutes, 1\%-100\% B; 4-7.5 minutes, 100\% B; 7.5-7.6 minutes, 100\%-1\% B; 7.610 minutes, $1 \%$ B. Injection volume: $5 \mu \mathrm{L}$. Dwelling time for each transition: 20 ms. Multiple reaction monitoring data were acquired using Analyst software (version 1.6.1, Applied Biosystems SCIEX).

Ribosome abundance. For sucrose gradient preparation, a 60\% sucrose solution was mixed with $10 \times$ gradient buffer $(200 \mathrm{mM}$ HEPES $\mathrm{pH} 7.6,1 \mathrm{M} \mathrm{KCl}, 50 \mathrm{mM} \mathrm{MgCl}, 100 \mu \mathrm{g} / \mathrm{mL}$ cycloheximide, EDTA-free proteinase inhibitor cocktail, $100 \mathrm{U} / \mathrm{mL}$ RNasin) and water to make $10 \%, 15 \%, 20 \%, 25 \%, 30 \%, 35 \%, 40 \%, 45 \%$, and $50 \%$ sucrose solutions. Then, $1.2 \mathrm{~mL}$ of each solution, starting with $50 \%$ sucrose, was 
carefully transferred to $12 \mathrm{~mL}$ Beckman tubes. To prevent diffusion, the gradients were flash-frozen in liquid nitrogen after each addition of solution, stored at $-80^{\circ} \mathrm{C}$, and thawed at $4^{\circ} \mathrm{C}$ overnight before use.

Cultures at $80 \%-90 \%$ confluency in $15 \mathrm{~cm}$ dishes were treated with $100 \mu \mathrm{g} / \mathrm{mL}$ cycloheximide (Sigma-Aldrich, C7698) for 5 minutes, washed twice, scraped, and collected in PBS containing $100 \mu \mathrm{g} / \mathrm{mL}$ cycloheximide. The cells were resuspended in $425 \mu \mathrm{L}$ hypotonic buffer $(5 \mathrm{mM}$ Tris- $\mathrm{HCl} \mathrm{pH} \mathrm{7.5,} 1.5 \mathrm{mM} \mathrm{KCl}, 2.5$ mM MgCl, $100 \mu \mathrm{g} / \mathrm{mL}$ cycloheximide, EDTA-free proteinase inhibitor cocktail [Sigma-Aldrich, 04693159001], $2 \mathrm{mMDTT}, 200 \mathrm{U} / \mathrm{mL}$ RNasin [Promega, N2111]), vortexed for 5 seconds, then supplemented with 0.5\% Triton X-100 (Sigma-Aldrich) and 0.5\% sodium deoxycholate (Sigma-Aldrich, D6750), vortexed for 5 seconds, and centrifuged at $21,000 \mathrm{~g}$ for 5 minutes to remove debris. Lysates were normalized by absorbance at $\mathrm{OD}_{260 \mathrm{~nm}}$ and loaded onto the $10 \%-50 \%$ sucrose gradient prepared above. The preparation was ultracentrifuged at 210,000 $\mathrm{g}$ at maximum radius for 2 hours using an SW41 Ti rotor in a Beckman XL-90 ultracentrifuge. Samples were then analyzed using the Bio-Rad BioLogic LP system with UV detector at room temperature, run with a $60 \%$ sucrose chasing solution at $1 \mathrm{~mL} /$ minute. Data were recorded in LP Data View. All procedures were performed at $4^{\circ} \mathrm{C}$.

OP-Puro incorporation assay. Cells were cultured and treated in 6-well dishes. Protein synthesis was assessed using the OPP protein synthesis kit (Invitrogen, C10457). Cells were incubated with $10 \mu \mathrm{M}$ OPP in culture medium at $37^{\circ} \mathrm{C}$ for 1 hour, followed by fixation in $0.5 \mathrm{~mL} 10 \%$ neutral-buffered formalin (Sigma-Aldrich, HT501128) at $4^{\circ} \mathrm{C}$ for 15 minutes, permeabilized in $0.1 \%$ saponin (Sigma-Aldrich, 47036) in $500 \mu \mathrm{L}$ PBS (Sigma-Aldrich, P4417) at room temperature for 5 minutes, and washed once with PBS. Fixed cells were resuspended and incubated in $500 \mu \mathrm{L}$ freshly prepared OPP reaction cocktail $(440 \mu \mathrm{L}$ reaction buffer, $10 \mu \mathrm{L}$ copper protectant, $1.25 \mu \mathrm{L}$ picolyl azide, $50 \mu \mathrm{L}$ reaction buffer additive) in the dark at room temperature for 30 minutes, washed with $0.5 \mathrm{~mL}$ rinse buffer, resuspended in PBS, and kept on ice before FACS analysis.

Celigo cell viability assay. $2 \times 10^{4}$ to $5 \times 10^{4} / \mathrm{mL}$ cells were plated in 96-well plates in $100 \mu \mathrm{L} /$ well and cultured overnight, then drugs were added in $100 \mu \mathrm{L} /$ well. After another 72 hours, $1 \mu \mathrm{g} / \mathrm{mL}$ propidium iodide and $5 \mu \mathrm{g} / \mathrm{mL}$ Hoechst 33342 were added and the plate was incubated at $37^{\circ} \mathrm{C}$ for 30 minutes. Hoechst-positive minus propidium iodide-positive cells were counted with a Celigo imaging system. For $\mathrm{IC}_{50}$ calculation, a log(inhibitor) versus response model (variable slope, 4 parameters), nonlinear least-squares fit (constrain top to 1 , bottom to 0) was performed in GraphPad Prism.

Immunofluorescence. 30\%-50\% confluent cultures were prepared on chamber slides (Thermo Fisher Scientific, 154534PK). Cells were fixed in $250 \mu \mathrm{L} \mathrm{10 \%}$ neutral-buffered formalin (Sigma-Aldrich, HT501128) for 10 minutes, washed once in $500 \mu \mathrm{L}$ PBS (Sigma-Aldrich, P4417), permeabilized, and blocked for 1 hour in $250 \mu \mathrm{L}$ staining buffer $(0.5 \%$ Triton $\mathrm{X}-100,10 \%$ goat serum in PBS). Fixed cells were incubated with primary antibody at 1:500 dilution in $250 \mu \mathrm{L}$ staining buffer at $4^{\circ} \mathrm{C}$ overnight and washed 3 times in $500 \mu \mathrm{L}$ PBS for 5 minutes each. Incubation with the secondary antibody (1:500 dilution in $250 \mu \mathrm{L}$ staining buffer) occurred for 1 hour, then the slides were washed 3 times in $500 \mu \mathrm{L}$ PBS for 5 minutes each. The washed slides were then incubated with $1 \mu \mathrm{g} / \mathrm{mL}$ DAPI in $500 \mu \mathrm{L}$ PBS for 1 minute. The chambers were removed and coverslips were mounted onto the slides and stored at $4^{\circ} \mathrm{C}$ before microscopic imaging. All procedures were done at room temperature unless specified.

ChIP- $q P C R$. First, $1 \times 10^{7}$ cells were crosslinked with $1 \%$ formaldehyde for 10 minutes and quenched with $0.125 \mathrm{M}$ glycine for 5 minutes.
The cells were washed twice with ice-cold PBS and lysed in $400 \mu \mathrm{L}$ sonication buffer for 15 minutes at $4^{\circ} \mathrm{C}$. The lysate was sonicated to shear chromatin fragments to an average size of about 200-500 bp (Branson Sonifier 450 ultrasonic processor, 20\% amplitude, 0.5 seconds on $1 \mathrm{sec}-$ ond off for 30 seconds). Sonicated lysates were centrifuged at 12,000 $\mathrm{g}$ for 10 minutes at $4^{\circ} \mathrm{C}$ to remove debris. Next, $150 \mu \mathrm{L}$ supernatant was supplemented with sodium chloride to $150-300 \mathrm{mM}$ and incubated with $1.5 \mu \mathrm{L}$ anti-RPA 1 antibody or rabbit IgG overnight at $4^{\circ} \mathrm{C}$. Dynabeads Protein $\mathrm{G}$ was prewashed 3 times with RIPA 0.3 buffer and $150 \mu \mathrm{L}$ binding mixture was incubated with $10 \mu \mathrm{L}$ Dynabeads Protein G for 2 hours at $4^{\circ} \mathrm{C}$. The beads were washed 3 times with $1 \mathrm{~mL}$ RIPA 0.3 buffer and twice with $1 \mathrm{~mL}$ TE buffer. They were then shaken at 1000 rpm with $80 \mu \mathrm{L}$ SDS elution buffer overnight at $65^{\circ} \mathrm{C}$ to reverse crosslinking and treated with 1 $\mu \mathrm{L} 20 \mathrm{mg} / \mathrm{mL}$ protease $\mathrm{K}$ for 30 minutes at $37^{\circ} \mathrm{C}$ to improve DNA recovery. DNA fragments were purified using QIAquick spin columns (QIAGEN) and eluted with $50 \mu \mathrm{L}$ water. Primers targeting pre-rRNA or IGS sequences were used for qPCR analysis using CYBR Green PCR system ( $5 \mu \mathrm{L}$ SYBR Green mix, $0.4 \mu \mathrm{L} 10 \mu \mathrm{M}$ primers mix, $4.6 \mu \mathrm{L}$ eluted DNA).

$R T-q P C R$. Oligonucleotide sequences are provided in Supplemental Table 1. Cultured cells were homogenized directly in $1 \mathrm{~mL}$ TRIzol (Invitrogen, 15596-026). Next, $20 \mathrm{mg}$ tumor fractions were flash-frozen in liquid nitrogen, followed by homogenization in $1 \mathrm{~mL}$ TRIzol using the Precellys tissue-homogenizing mixed-beads kit (Cayman Chemical, 10409). Before phase separation, TRIzol lysate was vortexed for $10 \mathrm{sec}-$ onds and combined with $0.2 \mathrm{~mL}$ chloroform (Thermo Fisher Scientific, S25248). The mixture was centrifuged at $12,000 \mathrm{~g}$ for 15 minutes at $4^{\circ} \mathrm{C}$, then the aqueous phase was collected and mixed with $0.5 \mathrm{~mL}$ isopropanol (Thermo Fisher Scientific, A451-1). RNA was precipitated by centrifugation at $12,000 \mathrm{~g}$ for 10 minutes at $4^{\circ} \mathrm{C}$, then washed in $1 \mathrm{~mL} 75 \%$ ethanol and dissolved in $100 \mu \mathrm{L}$ deionized water at $55^{\circ} \mathrm{C}$ for 5 minutes. Next, 500 ng total RNA was reverse-transcribed to cDNA in a $20 \mu \mathrm{L}$ reaction (4 $\mu \mathrm{L}$ iScript reverse transcription supermix [Bio-Rad, 1708841], 1-1000 ng RNA) at $25^{\circ} \mathrm{C}$ for 5 minutes, $46^{\circ} \mathrm{C}$ for 20 minutes, and $95^{\circ} \mathrm{C}$ for $1 \mathrm{~min}$ ute, then diluted 1:5 with deionized water. Target cDNA sequences were amplified in a $10 \mu \mathrm{L} \mathrm{qPCR} \mathrm{reaction}(5 \mu \mathrm{L}$ SYBR green supermix [Bio-Rad, 1725121], $0.675 \mu \mathrm{L} 2.5 \mu \mathrm{M}$ primer mix, $0.45 \mu \mathrm{L}$ diluted cDNA) at $95^{\circ} \mathrm{C} \times$ 10 seconds and $60^{\circ} \mathrm{C} \times 30$ seconds, for 40 cycles.

$I P$. First, $1 \times 10^{7}$ cells were washed with ice-cold PBS and lysed in $500 \mu \mathrm{L}$ CHAPS buffer supplemented with protease inhibitor cocktail for 30 minutes at $4^{\circ} \mathrm{C}$. Lysates were centrifuged at 20,000g for 10 minutes at $4^{\circ} \mathrm{C}$. Next, $50 \mu \mathrm{L}$ supernatants were aliquoted as input sample and supplemented with SDS sample buffer, then incubated for 10 minutes at $95^{\circ} \mathrm{C}$. Protein G Dynabeads (Thermo Fisher Scientific, $10004 \mathrm{D})$ were washed once with washing buffer to reduce nonspecific binding. Next, $450 \mu \mathrm{L}$ supernatants were transferred and incubated with $20 \mu \mathrm{L}$ Protein G Agarose Beads and rabbit polyclonal anti-RPA1 IgG (Abcam, ab241950) at $5 \mu \mathrm{g} / \mathrm{mg}$ of lysate overnight at $4^{\circ} \mathrm{C}$. The beads were washed 3 times with washing buffer and incubated with $50 \mu \mathrm{L}$ SDS sample buffer for 10 minutes at $95^{\circ} \mathrm{C}$. The IP complex and $10 \mu \mathrm{g}$ input samples were then subjected to Western blot analysis.

GTP pulldown. First, $1 \times 10^{7}$ cells were washed with ice-cold PBS and lysed in $500 \mu \mathrm{L}$ CHAPS buffer supplemented with protease inhibitor cocktail for 30 minutes at $4^{\circ} \mathrm{C}$. Lysates were centrifuged at 20,000 $g$ for 10 minutes at $4^{\circ} \mathrm{C}$. Next, $50 \mu \mathrm{L}$ supernatants were aliquoted as input sample, supplemented with SDS sample buffer, and incubated for 10 minutes at $95^{\circ} \mathrm{C}$. GTP-conjugated agarose beads (Axxora, JBS-AC-106S) were washed once with washing buffer to reduce nonspecific binding. 
Then, $250 \mu \mathrm{L}$ supernatants were transferred and incubated with $20 \mu \mathrm{L}$ GTP-conjugated agarose beads with or without $1 \mathrm{mM}$ GTP overnight at $4^{\circ} \mathrm{C}$. The beads were then washed 3 times with washing buffer and incubated with $50 \mu \mathrm{L}$ SDS sample buffer for 10 minutes at $95^{\circ} \mathrm{C}$. The IP complex and $10 \mu$ input samples were subjected to Western blot analysis.

Western blot. Protein lysates were prepared in RIPA buffer, supplemented with PhosSTOP phosphatase and cOmplete protease inhibitor cocktail (Roche, 11873580001, 04906845001). Total protein abundance was quantified by bicinchoninic acid assay. Next, 5-10 $\mu \mathrm{g}$ total protein samples were separated on 4-20\% SDS-PAGE gels, transferred to PVDF membranes, and probed with antibodies listed in Supplemental Table 2. Bands were detected with the ECL blotting system (Pierce, 32106).

Statistics. No methods were used to predetermine sample size. Samples for metabolomics and isotope tracing were randomized before LC-MS/MS analysis. For tumor growth experiments, mice were randomized before being allocated to cages for treatment. All other experiments were nonrandomized and did not involve blinding of the investigators. To assess statistical significance between 2 groups, a 2 -tailed Student's $t$ test was used. A $P$ value less than 0.05 was considered significant. Where data showed a skewed distribution, a Wilcoxon signed-rank test was performed. To examine significance in xenograft tumors between 2 groups, a 2-way ANOVA followed by Tukey's multiple-comparison test was performed. Before applying an ANOVA, we first tested whether there was homogeneity of variation among the groups using the Brown-Forsythe test.

Study approval. The protocol for collecting human SCLC tumor tissue for research was approved by the Ethics Committees of Tongji Medical College, Huazhong University of Science and Technology, and Tianjin Medical College. Written informed consent was obtained prior to participant inclusion in the study. Specimen collection did not interfere with standard diagnostic and therapeutic procedures. All mouse procedures were performed with the approval of the University of Texas Southwestern Medical Center IACUC.

\section{Author contributions}

$\mathrm{FH}$ and RJD conceived the project, designed and interpreted the experiments, and wrote the paper. $\mathrm{FH}$ performed experiments. JDM, AFG, TGO, ASI, and KEH provided cells and expertise in lung cancer. $\mathrm{HZ}$ and AC provided LAP-MYC mice and assisted in those experiments. $\mathrm{BD}, \mathrm{LAB}, \mathrm{CAS}$, and $\mathrm{KC}$ provided data from patient-derived xenografts. $\mathrm{YL}$ and $\mathrm{QY}$ provided expertise in ribosome measurements. ZW, XW, KL, LC, CY, TSS, MN, MDC, JX, and LGZ assisted in data acquisition and interpretation. XW provided facilities and assisted in processing human SCLC samples. LZ and FC performed metabolomics and isotope tracing.

\section{Acknowledgments}

We thank the DeBerardinis laboratory, Davide Ruggero, Elliott Ross, and Aron Jaffe for feedback. RJD is the Robert L. Moody Sr. Faculty Scholar and Joel B. Steinberg Chair in Pediatrics. He is supported by the Howard Hughes Medical Institute and grants from the NIH (1R35CA22044901) and Cancer Prevention and Research Institute of Texas (CPRIT RP160089). JDM is supported by the University of Texas Specialized Programs of Research Excellence (SPORE) (P50CA70907) and SCLC U24 CA213274 grants. TGO was supported by ACS Research Scholar Award RSG-13-300-01TBG, NIH award U01 CA231844, and the Damon Runyon Cancer Research Foundation DRR-26-13.

Address correspondence to: Ralph J. DeBerardinis, University of Texas Southwestern Medical Center, 6000 Harry Hines Blvd, Dallas, Texas 75390, USA. Phone: 214.648.2361; Email: ralph. deberardinis@utsouthwestern.edu.
1. Dang CV. MYC on the path to cancer. Cell. 2012;149(1):22-35.

2. Schaub FX, et al. Pan-cancer alterations of the MYC oncogene and its proximal network across the Cancer Genome Atlas. Cell Syst. 2018;6(3):282-300.e2.

3. Herranz D, et al. A NOTCH1-driven MYC enhancer promotes $\mathrm{T}$ cell development, transformation and acute lymphoblastic leukemia. Nat Med. 2014;20(10):1130-1137.

4. Muncan V, et al. Rapid loss of intestinal crypts upon conditional deletion of the Wnt/Tcf-4 target gene c-Myc. Mol Cell Biol. 2006;26(22):8418-8426.

5. Gabay M, Li Y, Felsher DW. MYC activation is a hallmark of cancer initiation and maintenance. Cold Spring Harb Perspect Med. 2014;4(6):a014241.

6. Vita M, Henriksson M. The Myc oncoprotein as a therapeutic target for human cancer. Semin Cancer Biol. 2006;16(4):318-330.

7. Whitfield JR, Beaulieu ME, Soucek L. Strategies to inhibit Myc and their clinical applicability. Front Cell Dev Biol. 2017;5:10.

8. Dang CV, Reddy EP, Shokat KM, Soucek L. Drugging the 'undruggable' cancer targets. Nat Rev Cancer. 2017;17(8):502-508.

9. Wolf E, Lin CY, Eilers M, Levens DL. Taming of the beast: shaping Myc-dependent amplification.
Trends Cell Biol. 2015;25(4):241-248.

10. Liu YC, et al. Global regulation of nucleotide biosynthetic genes by c-Myc. PLoS One. 2008;3(7):e2722.

11. Mannava S, et al. Direct role of nucleotide metabolism in C-MYC-dependent proliferation of melanoma cells. Cell Cycle. 2008;7(15):2392-2400.

12. Xiang Y, et al. Targeted inhibition of tumorspecific glutaminase diminishes cellautonomous tumorigenesis. JClin Invest. 2015;125(6):2293-2306.

13. Patra KC, et al. Hexokinase 2 is required for tumor initiation and maintenance and its systemic deletion is therapeutic in mouse models of cancer. Cancer Cell. 2013;24(2):213-228.

14. Xie H, et al. Targeting lactate dehydrogenase-A inhibits tumorigenesis and tumor progression in mouse models of lung cancer and impacts tumorinitiating cells. Cell Metab. 2014;19(5):795-809.

15. Wang YH, et al. Cell-state-specific metabolic dependency in hematopoiesis and leukemogenesis. Cell. 2014;158(6):1309-1323.

16. Stine ZE, Walton ZE, Altman BJ, Hsieh AL, Dang CV. MYC, metabolism, and cancer. Cancer Discov. 2015;5(10):1024-1039.

17. Hofmann JW, et al. Reduced expression of MYC increases longevity and enhances healthspan. Cell. 2015;160(3):477-488.
18. Johnston LA, Prober DA, Edgar BA, Eisenman RN, Gallant P. Drosophila myc regulates cellular growth during development. Cell. 1999;98(6):779-790.

19. Gomez-Roman N, Grandori C, Eisenman RN, White RJ. Direct activation of RNA polymerase III transcription by c-Myc. Nature. 2003;421(6920):290-294.

20. Grandori C, et al. c-Myc binds to human ribosomal DNA and stimulates transcription of rRNA genes by RNA polymerase I. Nat Cell Biol. 2005;7(3):311-318.

21. van Riggelen J, Yetil A, Felsher DW. MYC as a regulator of ribosome biogenesis and protein synthesis. Nat Rev Cancer. 2010;10(4):301-309.

22. Teleman AA, Hietakangas V, Sayadian AC, Cohen SM. Nutritional control of protein biosynthetic capacity by insulin via Myc in Drosophila. Cell Metab. 2008;7(1):21-32.

23. Masui K, et al. mTOR complex 2 controls glycolytic metabolism in glioblastoma through FoxO acetylation and upregulation of c-Myc. Cell Metab. 2013;18(5):726-739.

24. Cianfanelli V, et al. AMBRA1 links autophagy to cell proliferation and tumorigenesis by promoting c-Myc dephosphorylation and degradation. Nat Cell Biol. 2015;17(1):20-30.

25. Gazdar AF, Bunn PA, Minna JD. Small-cell 
lung cancer: what we know, what we need to know and the path forward. Nat Rev Cancer. 2017;17(12):725-737.

26. Rudin CM, Poirier JT. Small-cell lung cancer in 2016: shining light on novel targets and therapies. Nat Rev Clin Oncol. 2017;14(2):75-76.

27. Semenova EA, Nagel R, Berns A. Origins, genetic landscape, and emerging therapies of small cell lung cancer. Genes Dev. 2015;29(14):1447-1462.

28. Rudin CM, et al. Molecular subtypes of small cell lung cancer: a synthesis of human mouse model data. Nat Rev Cancer. 2019;19(5):289-297.

29. Mollaoglu G, et al. MYC drives progression of small cell lung cancer to a variant neuroendocrine subtype with vulnerability to aurora kinase inhibition. Cancer Cell. 2017;31(2):270-285.

30. Chalishazar MD, et al. MYC-driven small-cell lung cancer is metabolically distinct and vulnerable to arginine depletion. Clin Cancer Res. 2019;25(16):5107-5121.

31. Huang F, et al. Inosine monophosphate dehydrogenase dependence in a subset of small cell lung cancers. Cell Metab. 2018;28(3):369-382.e5.

32. Gazdar AF, Carney DN, Nau MM, Minna JD. Characterization of variant subclasses of cell lines derived from small cell lung cancer having distinctive biochemical, morphological, and growth properties. Cancer Res. 1985;45(6):2924-2930.

33. Johnson BE, et al. MYC family oncogene amplification in tumor cell lines established from small cell lung cancer patients and its relationship to clinical status and course. JClin Invest. 1987;79(6):1629-1634

34. Johnson BE, et al. MYC family DNA amplification in 126 tumor cell lines from patients with small cell lung cancer. J Cell Biochem Suppl. 1996;24:210-217.

35. George J, et al. Comprehensive genomic profiles of small cell lung cancer. Nature. 2015;524(7563):47-53.

36. Singleton KR, et al. Melanoma therapeutic strategies that select against resistance by exploiting MYC-driven evolutionary convergence. Cell Rep. 2017;21(10):2796-2812.

37. Stewart CA, et al. Single-cell analyses reveal increased intratumoral heterogeneity after the onset of therapy resistance in small-cell lung cancer. Nat Cancer. 2020;423-436.

38. Drapkin BJ, et al. Genomic and functional fidelity of small cell lung cancer patient-derived xenografts. Cancer Discov. 2018;8(5):600-615.

39. McFadden DG, et al. Genetic and clonal dissection of murine small cell lung carcinoma progression by genome sequencing. Cell. 2014;156(6):1298-1311.

40. Zhou K, et al. Modular degradable dendrimers enable small RNAs to extend survival in an aggressive liver cancer model. Proc Natl Acad Sci US A. 2016;113(3):520-525.

41. Kofuji S, et al. IMP dehydrogenase-2 drives aberrant nucleolar activity and promotes tumorigenesis in glioblastoma. Nat Cell Biol. 2019;21(8):1003-1014.

42. Grossman RL, et al. Toward a shared vision for cancer genomic data. N Engl J Med. 2016;375(12):1109-1112.

43. Signer RA, Magee JA, Salic A, Morrison SJ. Haematopoietic stem cells require a highly regulated protein synthesis rate. Nature. 2014;509(7498):49-54

44. Kusnadi EP, Hannan KM, Hicks RJ, Hannan RD, Pearson RB, Kang J. Regulation of rDNA transcription in response to growth factors, nutrients and energy. Gene. 2015;556(1):27-34.

45. Munro HN, Baliga BS, Pronczuk AW. In vitro inhibition of peptide synthesis and GTP hydrolysis by cycloheximide and reversal of inhibition by glutathione. Nature. 1968;219(5157):944-946.

46. Sanij E, et al. A novel role for the Pol I transcription factor UBTF in maintaining genome stability through the regulation of highly transcribed Pol II genes. Genome Res. 2015;25(2):201-212.

47. Schweppe DK, Huttlin EL, Harper JW, Gygi SP. BioPlex display: an interactive suite for largescale AP-MS protein-protein interaction data. J Proteome Res. 2018;17(1):722-726.

48. Calera MR, et al. Parcs/Gpn3 is required for the nuclear accumulation of RNA polymerase II. Biochim Biophys Acta. 2011;1813(10):1708-1716.

49. Carré C, Shiekhattar R. Human GTPases associate with RNA polymerase II to mediate its nuclear import. Mol Cell Biol. 2011;31(19):3953-3962.

50. Niesser J, Wagner FR, Kostrewa D, Mühlbacher W, Cramer P. Structure of GPN-Loop GTPase $\mathrm{Npa} 3$ and implications for polymerase II assembly. Mol Cell Biol. 2015;36(5):820-831.

51. Cristóbal-Mondragón GR, et al. FRET-based analysis and molecular modeling of the human GPN-loop GTPases 1 and 3 heterodimer unveils a dominant-negative protein complex. FEBS J. 2019;286(23):4797-4818.

52. Gras S, et al. Structural insights into a new homodimeric self-activated GTPase family. EMBO Rep. 2007;8(6):569-575.

53. Lin CY, et al. Transcriptional amplification in tumor cells with elevated c-Myc. Cell. 2012;151(1):56-67.

54. Kim S, Li Q, Dang CV, Lee LA. Induction of ribosomal genes and hepatocyte hypertrophy by adenovirus-mediated expression of c-Myc in vivo. Proc Natl Acad Sci U S A. 2000;97(21):11198-11202.

55. Orsolic I, Jurada D, Pullen N, Oren M, Eliopoulos AG, Volarevic S. The relationship between the nucleolus and cancer: current evidence and emerging paradigms. Semin Cancer Biol. 2016;37-38:36-50.

56. Tsherniak A, et al. Defining a cancer dependency map. Cell. 2017;170(3):564-576.e16.

57. Barna M, et al. Suppression of Myc oncogenic activity by ribosomal protein haploinsufficiency. Nature. 2008;456(7224):971-975.

58. Murayama A, et al. Epigenetic control of rDNA loci in response to intracellular energy status. Cell. 2008;133(4):627-639.

59. Cunningham JT, Moreno MV, Lodi A, Ronen SM, Ruggero D. Protein and nucleotide biosynthesis are coupled by a single rate-limiting enzyme, PRPS2, to drive cancer. Cell. 2014;157(5):1088-1103.

60. Giaever G, et al. Functional profiling of the Saccharomyces cerevisiae genome. Nature. 2002;418(6896):387-391.

61. Nguyen le XT, et al. Regulation of ribosomal RNA synthesis in T cells: requirement for GTP and Ebp1. Blood.2015;125(16):2519-2529.

62. Polley E, et al. Small cell lung cancer screen of oncology drugs, investigational agents, and gene and microRNA expression. J Natl Cancer Inst. 2016;108(10).

63. Sos ML, et al. A framework for identification of actionable cancer genome dependencies in small cell lung cancer. Proc Natl Acad Sci US A. 2012;109(42):17034-17039.

64. Le A, et al. Inhibition of lactate dehydrogenase $\mathrm{A}$ induces oxidative stress and inhibits tumor progression. Proc Natl Acad Sci US A. 2010;107(5):2037-2042.

65. Shroff EH, et al. MYC oncogene overexpression drives renal cell carcinoma in a mouse model through glutamine metabolism. Proc Natl Acad Sci U S A. 2015;112(21):6539-6544.

66. Ilic N, Utermark T, Widlund HR, Roberts TM. PI3K-targeted therapy can be evaded by gene amplification along the MYC-eukaryotic translation initiation factor 4E (eIF4E) axis. Proc Nat Acad Sci U S A. 2011;108(37):E699-E708.

67. Shen A, et al. c-Myc alterations confer therapeutic response and acquired resistance to c-Met inhibitors in MET-addicted cancers. Cancer Res. 2015;75(21):4548-4559.

68. Valvezan AJ, et al. IMPDH inhibitors for antitumor therapy in tuberous sclerosis complex. JCI Insight. 2020;5(7):e135071.

69. Augustyn A, et al. ASCL1 is a lineage oncogene providing therapeutic targets for high-grade neuroendocrine lung cancers. Proc Natl Acad Sci US A. 2014;111(41):14788-14793.

70. Kim J, et al. CPS1 maintains pyrimidine pools and DNA synthesis in KRAS/LKB1-mutant lung cancer cells. Nature. 2017;546(7656):168-172.

71. Xia J, Wishart DS. Using MetaboAnalyst 3.0 for comprehensive metabolomics data analysis. Curr Protoc Bioinformatics. 2016;55:14.10.1-14.10.91. 